\title{
COMPOUND DEPRESSED FRACTURE OF THE SKULL
}

\author{
CEREBRAL ABSCESS; HERNIA CEREBRI; \\ RECOVERY
}

\begin{abstract}
WITH A CONSIDERATION OF THE SUBJECT OF HERNIA CEREBRI BASED UPON ONE HUNDRED AND NINE COLLEC'TED CASES
\end{abstract}

BY

R. LAWFORD KNAGGS

(COMMUNicated by Mr. BRYAN'T)

Received November 2nd, 1896-Read April 13th, 1897

JosepH G-, aged 31, fell from a coal stage upon his head on September 11th, 1894, in the morning, and was admitted soon after into the Leeds Infirmary. In Mr. Mayo Robson's absence he came under my care. He was suffering from concussion and a compound depressed fracture of the left parietal bone, with a lacerated skin wound, and there was, besides, right facial paresis. This was permanent, and it remained doubtful if it had not existed before the accident. Consciousness was completely VOL. LXXX. 
recovered soon after admission. Under ether the wound was enlarged, and all the depressed bone and loose fragments removed, an aperture about three inches by two being left. There was a slit in the dura mater about one third of an inch long, and on holding its edges aside a clean, small, incised wound was seen on the surface of the brain. Cerebro-spinal fluid escaped freely from this opening, but after closure by a catgut suture the flow almost stopped. The wound was then closed, every care being taken to render it aseptic. The temperature was $100^{\circ}$ on the 11th and 12th, and then fell to normal, and, with very slight variations, maintained a normal course during his stay in hospital. The wound suppurated, and a slough at the bottom of it took some time to get rid of, but by November 11th it had healed. In other respects the patient's progress had been satisfactory till October 3rd, when he did not feel well; on the 4th he had two, and on the 5th one convulsive seizure affecting all his limbs, but more particularly those on the right side. He was ordered half-drachm doses of bromide of potash, and no further recurrence took place. On October 10th the right arm was markedly weaker than the left, and his articulation was affected. On November 17th his defect is described: "He knows what he wants to say but his difficulty is to say it."

By the end of November, when he was discharged, the paresis of the arm had largely recovered and his speech was better, but a blurring of three quarters of the outline of the right optic disc had persisted unchanged for a month.

On December 25th he had three fits, and on January 10th three more. His speech was distinctly worse on January 16th, and his pulse 60 (Mist. Pot. Bromid.). On January 21st the soft parts over the gap in the skull were pushed out about a quarter of an inch, and he complained of pains at the back of the neck. He improved for a time, but on February 4th again complained of pains over the whole head and the back of the neck, and on the 
18th he was readmitted. The protrusion over the opening in the left parietal bone was tense, semi-fluctuating, and pulsated. It measured $3 \frac{1}{2}$ inches by $2 \frac{1}{2}$, had an elevation of three quarters of an inch, and corresponded with portion of the motor area. The pain in the head and neck varied in severity. There was double optic neuritis, more advanced in the left eye. Pulse 60, temp. $97 \cdot 5^{\circ}$. Urine contained a trace of albumen. Dynamometer : right, 60 lbs.; left, 56 lbs.

On the 23rd he had a bad night, the pain necessitating several doses of chloral. The following morning he became semi-comatose, and his arms, especially the left, were rigid. Soon after he was found by the nurse at the point of death, and our able resident surgical officer, $\mathrm{Mr}$. Walter Thompson, entering the ward at that moment, explored the swelling at once and drew off some pus. Then with his pocket-knife he made an incision into the tumour, and a quantity of matter, estimated at three quarters of an ounce, spurted out to a considerable distance. Artificial respiration was at once commenced, and in a few minutes the patient came round.

Shortly after, I found the healthy surface of the brain protruding through a widely gaping incision in the dura. There was a small laceration or cut on the exposed convolution. In the afternoon the patient had recovered some consciousness, but his breathing was slightly stertorous and deep. The protruding brain being more prominent and very fluctuant, I explored it to a depth of $1 \frac{1}{2}$ inches. McEwen's trocar seemed to enter a cavity and some pus came away in the groove at the end, and a bead of pus escaped on its withdrawal ; but no collection being reached, nothing further was attempted. The head had been shaved and a gauze dressing applied, after careful efforts to render the parts aseptic. At 10.30 p.m. intelligence had returned, and there was marked paresis of both right arm and leg.

He continued to mend, power slowly returning to the right limbs. On February 27th the hernia cerebri, which 
was situated on the centre of a general protrusion of soft parts corresponding to the aperture in the bone, measured 2 inches by 1 inch, and had a height of 1 inch. It had been gradually enlarging. On March 10th it overlapped the scalp at the lower part, and any attempt to diminish it by pressure caused it to flatten out. The patient's mental condition, which before and since the operation had been very dull, was now much improved. He read his paper and could appreciate a joke.

After this the right grasp became very feeble (Dyn. : 6 lbs., 11 lbs., 9 lbs., 14 lbs.). The weakness seemed to be chiefly in the forearm muscles, as the finger movements were feeble and uncertain, but he could exert a considerable pulling or pushing force.

The hernia became covered with granulations, but did not increase. On April 5th it first showed signs of beginning to shrink. On the 13th the patient had a fit when his friends were visiting him. It began by the right arm being thrown out. On the 29th, a sore throat and a rise of temperature accounted for the hernia, which had been slowly diminishing, puffing up to its original size, but it subsided in a day or two with the disappearance of the throat condition. The shrinkage continued, and by May 18th skin was beginning to spread up over the sides. There is little more to add. The tumour completely disappeared, and on July 7th the wound was healed and a depression instead of a fulness existed over the bony aperture. When he went home on August 3rd, his general condition was satisfactory in every respect; the optic neuritis was clearing up, his speech, though better, was still slow and hesitating, and for some time he had been making himself useful in the ward (Dyn.: right, 50; left, 60). ${ }^{1}$

When last seen, in July, 1896, he was in good health,

1 I should like to express my obligation to Mr. Walter Thompson, Mr. A.S. Robinson, and Mr. H. Clough for the care and attention they gave to the case and for many of the notes. Mr. Thompson's brilliant promptitude deserves my grateful recognition. 


\section{DESCRIPTION OF PLATES XXIV AND XXV.}

Compound Depressed Fracture of the Skull; Cerebral Abscess; Hernia Cerebri (R. Lawford KNaggs).

\section{Puate XXIV}

Fig. 1.-March 16th.

Fig. 2:-About March 16th.

\section{Plate XXV}

Fig. 3.-May 21st.

Fig. 4.-After leaving hospital. 

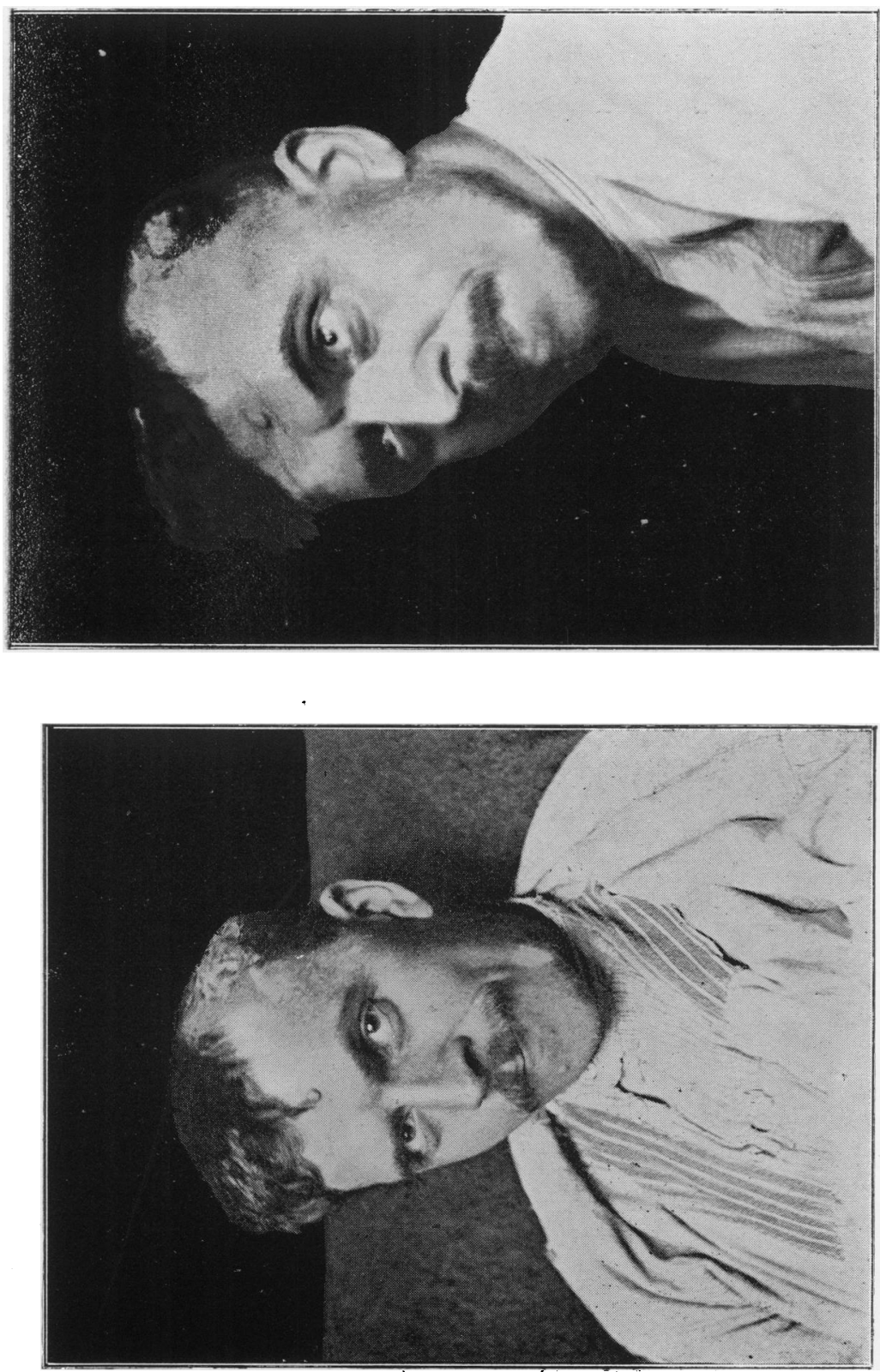

$\dot{\vec{L}}$ 

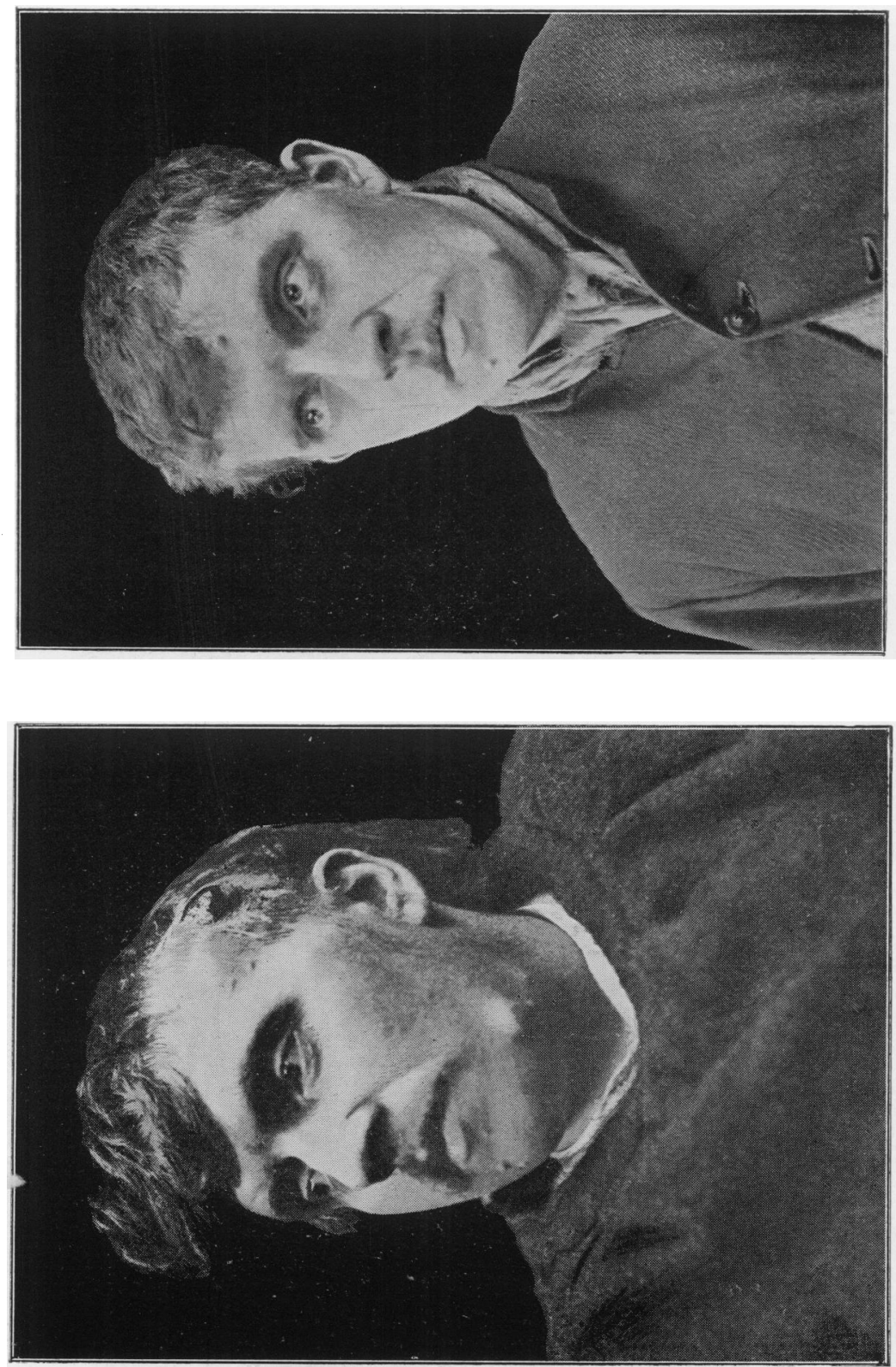
except that he had a fit every eight weeks. He was following some labouring employment, but his general condition was not materially altered.

The uncertainty that seemed to exist with regard to the most suitable treatment of hernia cerebri, an uncertainty that is well illustrated by the various methods that have been employed, induced the writer to investigate the subject.

The 109 cases upon which the following paper is based are in no way selected, except that those from German sources have necessarily been excluded from a want of knowledge of the language.

\section{Conditions antecedent to Hernia Cerebri.}

1. Compound fracture of the skull, frequently comminuted and usually depressed. (The membranes were probably injured in all, and in most cases the brain also) . . 80 cases.

2. Compound depressed fracture, where the membranes were intact, and subsequently gave way (Cases 11, 12, 22, 32 ?, 72, 96, $99)$. . . . . . 7 cases.

3. Simple fracture. The dura mater and brain were injured by a fragment (Case 41) . 1 case.

4. Fracture of inner table (Case 47) . . 1 case.

5. Scalp wound (Cases 17, 84) . . . 2 cases.

6. Necrosis-

(a) Syphilitic (Cases 90, 102)

(b) Traumatic (Case 78)

(c) "Disease of Bone" (Cases 55, 89) . $\}$

. $\{5$ cases.

7. Injury to brain, unprotected by a bony covering (Case 25) . . . . . 1 case.

In the remainder of the cases, information as to the exciting cause is absent. 


\section{The Intra-cranial Conditions predisposing to Hernia Cerebri.}

1. Increased tension.-The existence of this is sufficiently obvious, but it would probably not lead to hernia cerebri if it were not associated with the following. ${ }^{1}$

2. A softened or diffluent state of a portion of the cerebral substance.-This morbid condition would appear to be essential. It may be local, involving the protrusion and the adjacent portion of the brain, or it may be diffuse, involving large portions or the whole of a hemisphere. An area below the surface may be affected, and as it is moulded by the increased pressure, a crust of normal brain tissue may be pushed before it; thus the exterior of a hernia cerebri may be firmer than its centre (Cases 21, 90).

The softening, too, may be so extreme that the cerebrospinal fluid can open a track through it from the lateral ventricle to the surface (Cases 24, 96, 109).

In twenty-seven of the abstracted cases, direct evidence as to this softened state is forthcoming, and with a single exception this is post-mortem observation. Of the other fatal cases no post-mortem was made in twelve, and no notice is taken of the consistency of the brain substance in eleven. There remain three more. Two give us no help. They were recorded by Abernethy, who was responsible for certain views as to the causation of hernia cerebri. In the third (Case 62, recorded in 1830) it is stated that there was no alteration in the consistency of the brain; still, in that case an abscess containing three ounces of pus had been evacuated before death, so the accuracy of the observation is perhaps open to doubt.

3. Inflammation of the cerebral substance.-The softening of the brain tissue is a consequence of its inflammation. The increase in bulk, without which the hernia would not

I In connection with this point, attention may be drawn to those cases where the skull-cap is opened for brain tumour. Here the bulging of the brain into the aperture is hardly to be described as hernia cerebri, by which term we understand rather a protrusion. 
occur, is due to inflammatory exudation, which leads to a general softening of its tissues, and their replacement by granulation tissue, if the process is sufficiently prolonged. Where the brain has been extensively implicated, the hernia has usually been large, and, when removed, rapidly reproduced (Cases 98 to 101). This might be expected. More than one case is to be found in the appended list, in which after removal of the hernia or sloughing of its surface, a serous fluid has poured away from the exposed portion for a considerable time, and sometimes with relief to the pressure symptoms (Cases 17, 61, 64). In these cases the discharge was almost certainly the inflammatory exudation, and not cerebro-spinal fluid.

The causes of the inflammation are-

(1) Direct injury to the brain itself ;

(2) Traumatism, with sepsis added, and

(3) Sepsis alone ;

and as a consequence of it, the functions of the area involved are affected, being weakened, or in complete abeyance, and in the worst cases even destroyed more or less completely.

When the motor area is affected, the extension of the disease may be followed as fresh symptoms gradually supervene, and its recession may be traced as symptoms in order decline and disappear.

An extension of the inflammatory œdema to the neighbourhood of the iter may lead to the occlusion of a passage through which the inflammatory serum discharged into the ventricles is usually carried away, and so produce not only a possible aggravation of the symptoms, but a prolongation of the period of subsidence. ${ }^{1}$

\section{The Size of the Opening in the Skull.}

There is nothing in the cases here brought together that would seem to support Guthrie's belief that hernia cerebri is more likely to occur with a small opening than

$$
1 \text { ' Brain,' 1893, p. } 222 .
$$


with a large one. But it must be admitted that a small aperture is more likely to be the result of a concentrated force and to be associated with injuries to the brain and its membranes; whilst in such a wound there is more danger of sources of irritation, such as detached portions of inner table, being left in situ.

\section{The Course of Hernia Cerebri.}

Hernia cerebri being due to increased bulk consequent upon inflammatory effusion into the brain tissue, will in due time shrink and disappear, as the inflammatory process subsides and the effusion becomes absorbed.

The time required varies, and will depend upon (1) the extent to which the brain is affected, and (2) the absence or presence of continued irritation. It may be a question of a week or two, or possibly of several months. So long, however, as sepsis is avoided this course may be counted upon. But if septic infection should take place, then the outlook is extremely serious. The forms which it may take, viz. meningitis, abscess, and diffuse inflammation, will be discussed elsewhere, but here it may be stated that in abscess only-and then only in a proportion of cases-can there be any hope of saving the patient.

Many of the cases quoted, when of short duration, are probably examples of resolution. Case 10 is evidence of cicatrisation; and of suppuration there are many instances.

\section{Conditions complicating Hernia Cerebri.}

1. An occasional consequence is a predisposition to hæmorrhage which takes place into the softened patch, and may cause serious external bleeding. This is, no doubt, due to the vessels in the inflamed area sharing in the general softening and losing the support of the healthy tissue. The onset of hæmorrhage may lead to a sudden increase in size of the protrusion, and Abernethy meeting with two cases of this nature was led to look upon it as 
the cause, and not an occasional complication of hernia cerebri.

2. Very sudden enlargement of the tumour may arise from quite trivial causes. Thus, in G-'s case it occurred in connection with a sore throat and a rise of temperature, and in Case 75 it followed an examination of the parts with a probe.

3. The influence of gravity must not be overlooked when the aperture in the skull is low down on the vertex or at the base. If the brain substance were very diffluent the tendency would be for it to pour out, rather than to rise out, of the brain case. The difficulty of managing a protrusion under such circumstances would be enhanced, and an element of danger introduced (Cases 34, 102).

\section{Hernia Cerebri and Abscess.}

The prolonged continuance of a large hernia cerebri, or its increase after it has existed for a long time, is nearly always due to some serious condition upon which the protrusion depends. This may be irritation in some form capable of removal (Cases 74, 75) or perhaps beyond the reach of it, but now-a-days, when thorough operations for depressed compound comminuted fractures are the rule, it is more likely to be due to abscess.

It has been stated that a rapid increase in size of a hernia that has been long stationary, or is even shrinking, may result from some slight local or general cause, but an increase of this kind is only transient. The tumour soon returns to its original size.

The formation of a hernia cerebri after a considerable interval has elapsed since the original injury to which it is to be traced, is strongly in favour of abscess (G-'s case).

The question naturally suggests itself why in some cases of brain abscess hernia cerebri is such a marked and persistent feature, whilst in others there is only a slight bulging of the brain into the bony aperture. An explana- 
tion is probably to be found in the varying amount and degree of softening which surrounds the abscess or intervenes between it and the surface. On this point Cases 26 and 27 throw some light.

\section{Prognosis.}

So long as sepsis is avoided this is good, but when it is present it may take the form of-

1. Meningitis.-A condition always fatal. The infection may be received-

(a) In connection with the original injury, whether accidental or operative (Cases 21, 22).

(b) As a consequence of some operative interference with the hernia cerebri (Cases 96, 97).

(c) From an extension of the inflammation of the brain, which in such cases is, no doubt, of a septic nature.

2. Abscess.-This is very serious, but not necessarily fatal.

Recovery may take place-

(a) By spontaneous evacuation (Cases 17, 18).

(b) After surgical interference (Cases, G-'s, 78, 79).

Death may result-

(c) Notwithstanding surgical interference (Case 62).

(d) From rupture into the lateral ventricle (Cases 93, 94).

(e) From the supervention of meningitis (Cases 63, 64).

3. Very extensive disorganisation of the brain.-Probably most of the cases in which large areas of brain tissue are inflamed are septic, but that this is not always so, a case recorded in 'Brain" by Dr. Conyngham Brown and the writer clearly proves. This case will be referred to more fully, later.

$$
1 \text { 'Brain,' 1893, p. } 213 .
$$




\section{Analysis of Cases.}

Left to nature-34 cases; 19 recoveries, 15 deaths.

Recoveries-

(a) Receded gradually after formation of hernia cerebri

Cases.

(b) Ditto, but dura mater uninjured and gave way from internal pressure . . . 11, 12

(c) Hernia sloughed or separated . . . 13-15

(d) Hernia discharged foreign body and subsided . . . . . . 16

(e) Abscess spontaneously evacuated . . 17, 18

$(f)$ Insufficiently reported . . . . . 19

Deaths-

(g) Meningitis . . . . . . . 20-23

(h) Meningitis, large area of brain inflamed . 24, 25

(j) Abscess . . . . . . . . . 26, 27

(k) Abscess, pyæmia . $\quad . \quad$. $\quad$. $\quad$. 28

(l) Cause uncertain . . . . . . . . 29-34

The usual duration of a hernia cerebri, if not subjected to meddlesome surgery, and if recovery takes place, varies between a few days and a couple of months.

Excluding four instances (Cases 18, 19, 35, 37) in which the time is not stated, all the successful cases in this group and the next ran their course within these limits, with the exception of two, in one of which (Case 10) a -wedge of cicatricial tissue was found in the brain, some years later, at the site of the protrusion, and in the other (Case 17) the hernia subsided on the evacuation of an abscess. These two cases persisted for four months. Contrast this with the duration of the condition in the third group, in which caustic remedies were used. Only in four of the five recoveries is the time mentioned, but in one (Case 50) the patient was in hospital five months, and in another (Case 51) the hernia existed for double that period. 
Sepsis was responsible probably for all the fatal cases, and in the light of 'modern ideas it is likely enough that had it been possible to use the methods now in vogue, the number of deaths, and possibly the number of cases in which hernia cerebri developed would have been materially diminished.

Case 30, in which a compound depressed fracture was not operated upon for a fortnight, and until symptoms of mischief had made their appearance, is interesting as illustrating the importance of preventive treatment in another direction.

Cases in which Pressure was the chief treatment employed.

Recoveries 11, deaths 4.

Recoveries-

Cases.

(a) Where symptoms were already on the wane when pressure was used . . . $\quad$. 35, 36

(b) Where a source of irritation came away $\quad 37$

(c) Where pressure seemed to act well . . 38-40

(d) Where pressure probably influenced recovery but little

(e) Where a tendency to protrude continued for some time $\quad . \quad . \quad . \quad . \quad . \quad 44,45$ Deaths-

(f) Abscess . . . . . . . . . $46-48$

(g) Uncertain, probably abscess $\quad . \quad$. $\quad . \quad 49$

In this group also sepsis was the cause of every death. In one case ${ }^{1}$ (47) the result was unavoidable, but in the others early operation and asepsis might have produced different results.

But the eleven successful cases only represent a fraction of those in which pressure was employed. In many others it was tried and given up, but even in those cases in which it was the only active treatment, it was evident that the majority or all of them would have recovered without it.

1 Fracture of inner table. 
Its value, when it had any, probably lay in expediting the natural shrinkage of the tumour, and sometimes, perhaps, in preventing undue growth.

When the hernia has assumed a mushroom shape, its periphery overlapping the edges of the opening in the scalp, pressure is out of place, for it flattens out instead of repressing the growth.

There is, however, evidence to show that the employment of pressure, other than of a very gentle character, is likely to do more harm than good. In Case 11 the pressure exercised by the intact dura mater led to symptoms which were relieved when that membrane gave way and allowed the brain to protrude. In other cases pressure has had to be discontinued because it caused symptoms which were relieved on its removal (Cases 59, 94, 100). But perhaps the most serious result of pressure is the effect it may have in promoting the destruction and absorption of the softened brain tissue, and so favouring some future functional weakness. To illustrate this possible danger, the writer would refer to the case published in 'Brain,'" to which allusion has already been made.

Here the right hemisphere had evidently been the seat of a diffuse aseptic inflammation resulting from a fall. Some years afterwards both ventricles were found very much enlarged. The right ${ }^{2}$ was more enlarged than the left, ${ }^{3}$ and occupied almost the whole hemisphere. It was suggested that the unequal dilatation was the effect of increased intra-ventricular pressure acting upon softened brain upon one side, and normal brain on the other, and no doubt the cicatricial contraction of the inflammatory elements present on the right side had increased the disparity. In the end only a shell of hardened and condensed tissue enclosed the ventricle, and the patient suffered from hemiplegia and frequent convulsive seizures. Hernia cerebri has been compared to a safety-valve. In

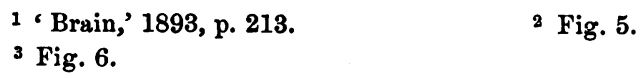




\section{COMPOUND DEPRESSED FRACTURE OF THE SKULL}

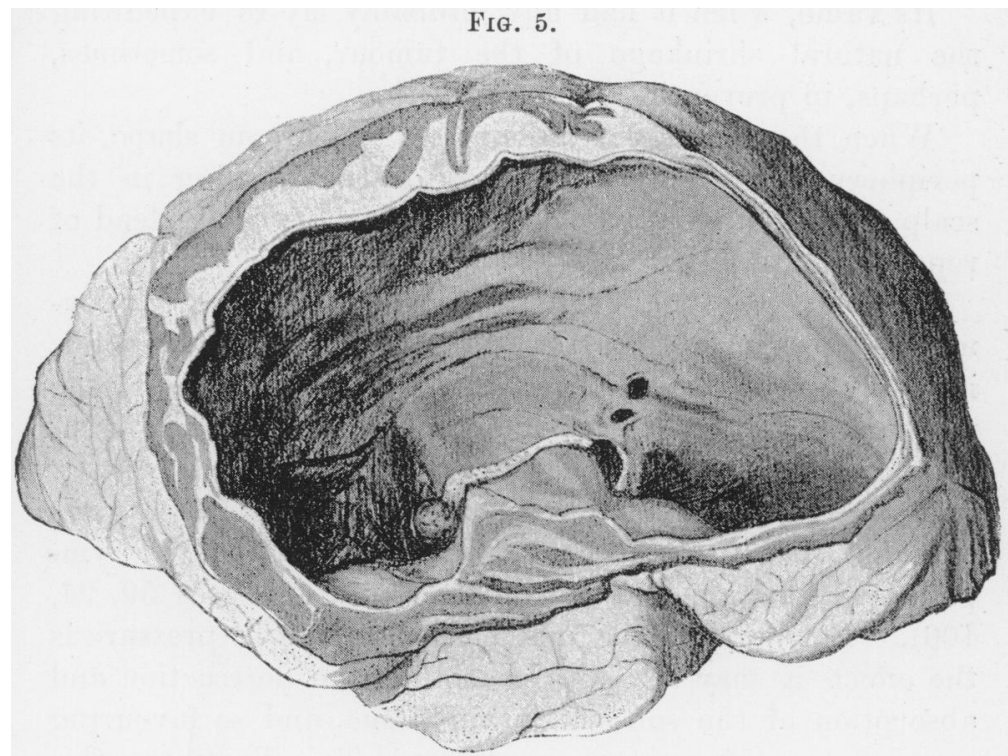

FIG. 6.

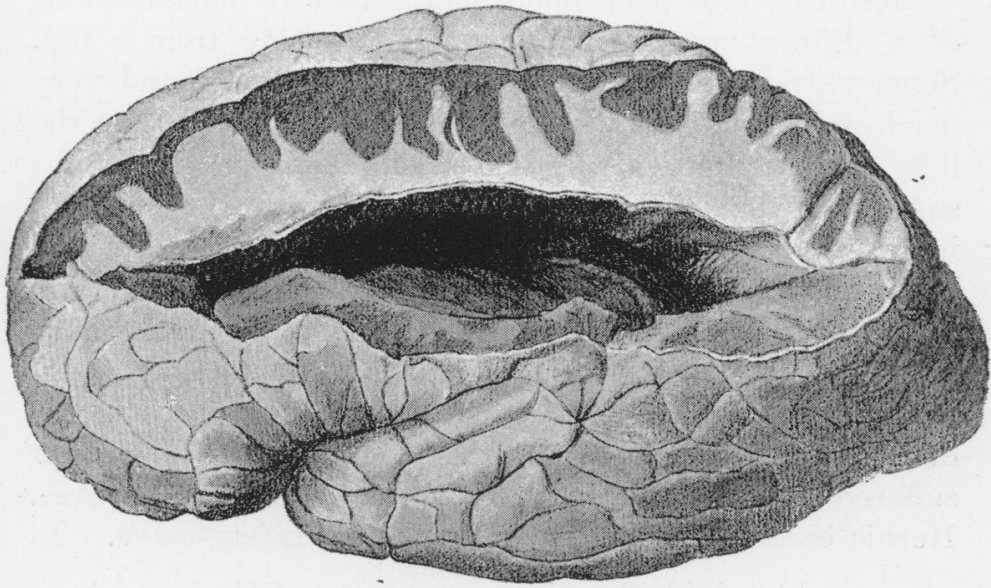

From 'Brain.' 
the case just narrated the condition was such as would have led to hernia cerebri had there been an aperture in the skull ; but how much less grave the subsequent changes would have been, if a large opening had permitted a free expansion of the swollen brain, can only be a matter for speculation.

Cases in which Caustics constituted the chief method of treatment.

Recoveries 5, deaths 2.

Recoveries -

Cases.

(a) Certainly no benefit . . . . $\quad$. 50, 51

(b) Probably no benefit . . . . . 52, 53

(c) Harm done . . . . . . . 54

In 3 of the above ( 1 in each division) pressure was combined with caustics.

Deaths-

(d) Meningitis . $\quad . \quad$. $\quad . \quad$. $\quad$ • 55

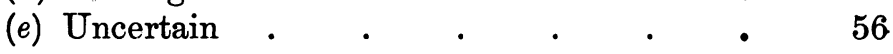

Of the deaths, certainly one and probably both were due to sepsis. Caustics were employed in many of the other cases without benefit, but in these, in which they were not followed by other more heroic methods of treatment, and in which recovery ensued, evidence of real benefit is absent. Indeed, in one instance, the patient was saved by the discontinuance of the treatment. Nor is this astonishing, for the frequent destruction of the surface, and the necessary separation of the slough, would be likely to keep the protruded brain in a constant state of irritation, favourable to a continuance of the inflammatory swelling, and to delay in its natural subsidence, at the same time that it would offer increased facilities for septic infection.

The five successful cases, therefore, may be fairly regarded as cures due to natural processes in spite of the treatment employed. 
Various Operative Procedures-not Removal. Recoveries 3, deaths 9 .

Recoveries-

(a) Transplanting skin flap . . . . $\quad$. 57

(b) Puncture by thermo-cautery . $\quad$. $\quad 58$

(c) Surface of hernia cerebri pared off daily, causing bloodletting. . . .

(d) Extensive laceration of brain, exploration for pus fourth day . $\quad . \quad$. $\quad .60$

(e) Large area of brain breaking down, top removed by spatula $\quad . \quad . \quad . \quad . \quad 61$

(f) Abscess, incision, rupture in lateral ventricle $\quad . \quad . \quad . \quad . \quad . \quad . \quad 62$

(g) Meningitis, abscess incised . . . 63,64 Ditto, subdural abscess opened, later interference with wound . . . 65

Ditto, hernia cerebri removed by patient's -fingers $^{1}$. $\quad . \quad . \quad . \quad$. $\quad . \quad 66$

Ditto, with pyæmia, laceration of hernia by patient's fingers . . . . 67

Ditto, with pyæmia, tumour incised . $\quad 68$

In this group all the recoveries were instances of natural cure, the treatment described being merely unnecessary incidents in the course of the cases. With one exception (Case 60), the fatal cases were due to sepsis, and the suspicion is naturally raised, though with how much justification it is difficult to be sure, that in some the septic infection may have been the result of the operative interference.

Removal of Tumour.

Recoveries 19, deaths 22.

Recoveries-

(a) After removal (5) . $69-73$

In two $(71,72)$ pressure subsequently

1 This case might perhaps m.ore correctly have been placed in the next division. 
employed ; in one (73) ligature used when tumour had become smaller.

(b) Source of irritation removed when excision was performed (4)

(i) Bony fragment in centre of tumour, arm remained paralysed (76).

(ii) Projecting or loose bone removed $(74,75)$.

(iii) Exit given to intra-cranial discharge (77).

(c) Excision followed by evacuation or drainage of abscess (2) . $\quad . \quad . \quad . \quad .78,79$

(d) Hernia removed more than once (in six several times) (8)

$.80-87$ Deaths-

(e) Abscess (5) . $\quad . \quad$. $\quad . \quad$. $\quad . \quad 88-92$ Ditto, rupture into ventricles (2) . . 93, 94

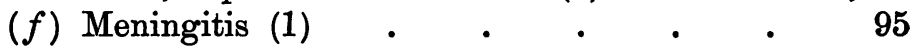
Ditto, probably induced by operative pro$\begin{array}{lllllll}\text { cedures (2) } & \text {. } & \text {. } & \text {. } & \text {. } 96,97\end{array}$

(g) Large area of brain disorganised or removed

(5) . . . . . . . 98-102

(h) Cause uncertain (7) . . . 103-109

Of the six cases included in groups $(b)$ and $(c)$, one (76) thoroughly justifies the radical treatment employed; two $(78,79)$ might possibly not have recovered without it as the abscesses presumably were deeply situated; and in two others $(74,75)$ under present methods no source of irritation would have been left. The other thirteen cases of recovery, groups $(a)$ and $(d)$, would probably have got well if left alone. In seven of them ${ }^{1}(72,80,81,83$,

1 In Case 72 on the 4th day, in Case 80 on the 12th and 25th days, in Case 81 on the 9th, 23rd, and 42nd days after the injury, in Case 83 several complete or partial removals before the 35th day after the injury, in Case 85 in u few days, and repeated every 2 or 3 days, in Case 86 early removal inferred (it was sliced off daily), in Case 87 on the 19th day, and repeated at intervals for 20 days.

The remarks upon the cases "left to nature" may be compared with these facts.

VOL. LXXX. 
$85,86,87$ ) removal was carried out much too soon for nature to have had a chance. In one (73) nature was doing its work, and in another (69) the continued irritation of caustics was probably preventing a natural subsidence. In the remaining four $(70,71,82,84)$ the details are insufficient for special comment, though an early resort to removal may be suspected.

Among the causes of death cerebral abscess occurs seven times $(88-94)$. In two $(93,94)$ rupture into the ventricles was an adequate explanation. In one (89) the discharge of the abscess during life did not prevent a fatal issue.

Meningitis was present in three cases, and probably in all was the essential factor in causing a fatal issue. In two of the three $(96,97)$, if not in the third, there is a strong suspicion that the removal of the tumour was to blame.

In Cases 98-102 death presumably was due to the large area of brain involved or removed. The salient features of this group are the frequency of interference and its early commencement (vide Case 100). This continued irritation, whilst increasing the dangers of sepsis, may in some degree account for the large amount of brain implicated. Had cleanliness and non-interference been relied upon, the results might have been more satisfactory.

The cause of death must, for want of definite statements, be put down as uncertain in seven cases (103-109), but we can well imagine that sepsis played its part in the majority. Thus in Cases 106 and 107, after active treatment extending over months, the patients succumbed probably to meningitis, for which surgical interference was most likely to blame. In Case 108, said to have died of abscess on the thirty-seventh day, the fungus was three times removed in that short time, and Case 109 lasted little more than a month, but removal of the tumour had led to opening of the lateral ventricle. In two of these cases hæmorrhage was important. Bleeding into and from the tumour led to its removal in Case 104, and in Case 105 the patient nearly bled to death from inability to stop it after excision. 
Table to show the Comparison between the Results due to Natural Processes and those following Operation.

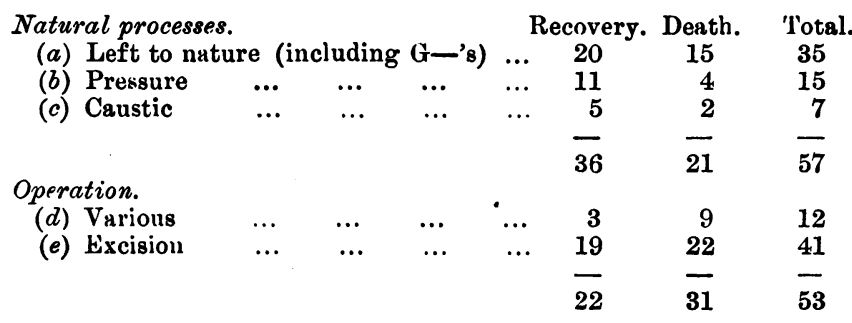

\section{Summary.}

From what has gone before it seems clear that in all the cases in which there was no operative interference, the successful issue was dependent upon natural processes. Pressure and caustics, though freely used, rarely seem to have given any real assistance, and the latter is especially to be condemned.

Then, of the cases treated by operation, the three successes under $(d)$ were really instances of natural subsidence, and of the nineteen successes following excision, thirteen at least would have ended in a natural cure if left alone. Of the other six, removal was of value in three, and perhaps the only way in which life could have been saved; but in the remainder, though of use, successful results might have been obtained in other ways without the mutilation of so important an organ as the brain-a mutilation which, it can hardly be doubted, caused a permanent paralysis more frequently than is stated.

Sepsis was answerable for the result in all the fatal cases with one or two exceptions, and in connection with this it is perhaps worth while to draw attention to the largely increased percentage of deaths ${ }^{1}$ in the operative cases, where opportunities for septic infection must have been largely increased.

1 The percentage of deaths in cases under heads $(a)(b)(c)$ was $35 \cdot 8$, whilst the percentage in the operative cases was $58^{\circ} \cdot 5$-an increase of $21 \cdot 7$. 


\section{The Treatment of Hernia Cerebri.}

1. Preventive treatment. (a) Asepsis.-As a very large proportion of these cases are due to traumatism, from which septic influences have not been successfully excluded, it is not only reasonable to hope, but it is certain, that very careful attention in rendering all injuries to the scalp and skull as aseptic as possible, must lead to a considerable diminution in the frequency of this condition.

(b) Thorough treatment of compound depressed fractures of the skull.-Of the 110 cases in the present paper, 88 owe their origin to compound depressed fractures. The present rule of practice to operate at once upon all cases of this kind is very salutary. The operation should be thorough, all loose fragments being removed. This, further, allows a more thorough cleansing of the wound. It is probably in consequence of the great care that is exercised in these two matters, that hernia cerebri is now so rarely seen, and that so few cases are to be found in recent literature.

2. Non-interference.-Except for rigid cleanliness and the careful exclusion of all septic influences, the safest rule of practice is to leave the protrusion to pursue its own course. A careful study of the material upon which this paper is based, brings out this point with great clearness.

3. Operative treatment. (a) When the tumour is associated with abscess.- Under these circumstances the policy of non-interference must be departed from. Treatment should aim at evacuation and drainage of the abscessnot removal of the tumour, which may contain important motor centres. A method which would entail permanent paralysis should not be entertained without very strong reasons. Spontaneous evacuation is too uncertain to be trusted to, and only likely to occur in those cases where surgical interference would be easy, and, if judicious, almost certainly successful.

(b) Apart from abscess the cases in which operative treatment is really justified must be excessively rare. 
Such a case was 76, where a fragment of bone was found embedded in the base of the tumour. Though in that instance the discovery was only made at the time of the operation, yet in the present day, by the use of the skiagraph, a similar condition could probably be diagnosed, and an attempt would then be made to extract the irritating body. If that were done the necessity for shaving off the protrusion would no longer exist.

\section{Abstracts on 109 Cases of Hernia Cerebri.}

\section{Cases left to Nature; Recoveries.}

Case 1. Fabrice de Hilden, Spring's paper, 'Mém. Acad. Royale de Méd. de Belge,'iii, p. 70, 1854, Obs. 44.-A young man developed a fungus as a result of fracture of the right parietal. In twentyfour hours it grew as big as a hen's egg. Powders and aromatic lotions were applied. It began to subside in fourteen days, and the wound was perfectly healed in two and a half months.

CAse 2. Hey, 'Practical Observations in Surgery,' p. 12.-Boy aged 14. Compound depressed fracture of right parietal bone, injury to dura mater, and wound of brain. Operation on fourth day. A fungus about the size of a large nutmeg arose from the brain, and had a strong pulsation. No pressure used. In three weeks it had subsided, and the wound then healed.

Case 3. Hey, ' Prac. Obs. in Surgery,' p. 14.-Boy aged 13. Compound depressed fracture of left parietal bone with lacerated wound of dura. Operation. Through the wounded dura an oblong fungus arose, but with simple dressings without pressure it retired as cica. trisation advanced. The boy got well.

CASE 4. 'Cooper's Surgical Dict.,' p. 691.-The only case Larry ('Mém. de Chir. Mil.,' t. 4, p. 206) ever saw recover was treated by a dressing of slightly camphorated oil of camomile, removing all kinds of irritation, and excluding air. The tumour was small.

CASE 5. Moyle, 'Lond. Med. Report,' vol. viii.-Boy aged 8. Compound depressed fracture of left side of frontal bone, with loss of 
brain substance ; compression. Trephined. On the third day hernia cerebri appeared, and increased to size of half an egg. The hernia retired by degrees as the wound cicatrised.

Some years later the boy was in good health.

CASE 6. P. P. Creagh, 'Med.-Chir. Trans.,' 1811, vol. ii, p. 53.November 20th. $-A$ wounded seaman had a depressed compound fracture involving chiefly the left parietal bone, the membranes and brain being injured by a splinter. Loose bones removed.

21st.-Brain substance protruding.

25th.-Paresis of one side (not stated). More loose fragments removed.

30th.-Lethargic; protrusion persists.

December 1st.-Convulsions; duzing and at times comatose; paralysis increased. More bone removed, exposing entirely the ruptured membranes, through which the brain protruded.

8th.-Paralysis much improved.

12th.-Protrusion receding.

18th.-Discharge from cerebrum slight and almost serous.

The sores bealed and the paralysis recovered.

CASE 7. MacGillivray, 'Australian Med. Journ.,' 1864, vol. ix,

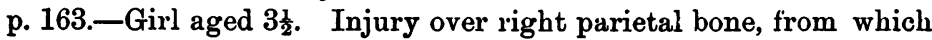
brain protruded on the second day, caused by pickaxe. Marked symptoms. No operative interference. Some bone exfoliated, and in a month hernia cerebri formed as big as a hazel-nut. It was stationary for four weeks, gradually diminished and disappeared, and the wound eventually healed.

CASE 8. Joseph Bell, ' Edin. Med. Journ,' 1868, vol. xiii, p. 1086. -A pril 13th.-Man aged 25, admitted for compound depressed fracture of right parieto-occipital region with injury of the dura mater, and penetration of brain by a small piece of bone. Loosened frag. ments were removed.

19th.-Brain protruding through dura mater.

23rd.- Hernia cerebri as large as half an apple.

29th.-Till this date he had had head symptoms, such as delirium. He now began to mend.

May 9th.-Hernia had disappeared, and the wound in dura was apparently closed. Recovery followed.

September 16th.-Left hospital, having been detained so long in consequence of a severe injury to the pelvis, which had complicated the head condition. 
Case 9. Berger, 'Bull. et Mem. de la Soc. de Chir. de Paris,' 1880, vol. vi, p. 253.-Boy, aged 13, came under treatment with a cerebral hernia as large as a hazel-nut, resulting from an untreated injury of the right frontal region four days before. After the removal of some fragments of bone, and liberation of some pus which lay between the dura mater and the brain, the hernia rapidly subsided, and serious symptoms disappeared. Cure resulted, but the mental condition remained impaired.

CAsE 10. John Duncan, 'Brain,' 1879-80, vol. ii, p. 413.-Boy aged 13. 1st day.-Pony kick caused compound depressed fracture of left frontal bone; portions of bone removed.

11th.-Hernia cerebri developed without symptoms.

21st.-As large as a small orange. For four months it remained stationary, only cleanliness being observed, then it dwindled.

6th month.-A level pulsating scar remained.

After-history.-Three years later he died of inherited phthisis.

Post-mortem.-A circular aperture 1 inch in diameter was found in the bone, and from this, as a base, an irregular cone of cicatricial tissue extended into the brain for $\frac{3}{4}$ inch. It occupied the centre of the second and part of the first convolution.

Case 11. Joseph Taylor, recorded by Stanley, 'Med.-Chir. Trans.,' vol. viii, p. 39.-Boy aged 10. 1st day.-Compound depressed fracture of left parietal bone.

3rd.-Trephined; compression symptoms continued.

7th.-Right facial paresis.

8th.-Tongue paralytic; curious brain symptoms; involuntary micturition. Improved in the evening; became compos; slept; paralysis less perceptible.

9th.-On removing dressings the dura was found to have ruptured, and natural and apparently healthy brain protruded to the size of a moderate hen's egg. Untoward symptoms had disappeared. Compression of the hernia caused restlessness and stupidity.

Wound healed rapidly.

24th.-Boy playing at marbles with his companions.

Case 12. Spanton, 'Lancet,' 1864, vol. i, p. 268.-August 6th.Boy aged 6. Compound depressed fracture of left side of frontal bone from a horse kick; compression. Operation by Mr. Favell; dura mater uninjured.

26th.-Progressed favorably, when to-day the dura mater gave way and brain protruded : free discharge of pus. The hernia reached 
the size of half a walnut, and was painted every other day with collodion.

October 22nd.-Surface of the wound level.

November and December.-Portions of necrosed bone came away.

December 31st.-Healed completely.

Case 13. G. Lowe, 'Lancet,' 1850, vol. i, p. 759.-A groom had a componnd comminuted fracture of the skull with laceration of brain from a horse's kick. A teaspoonful of brain substance was lost in removing a deeply embedded piece of bone.

Inflammation of the brain came on with drowsiness; great slowness of reply and sickness; and in ten days a hernia cerebri formed, which at last attained the size of a walnut. On the fourteenth day, under mercury, symptoms abated; the tumour shrank considerably, and finally sloughed away. Recovery was perfect.

Case 14. From medical commentaries, Stanley, 'Med.-Chir. Trans..' vol. viii, p. 38.-Protrusion of brain began on the fourth day, and increased gradually till the fourteenth, when it spontaneously dropped off in pretty large pieces. Only treatment dry lint dressing.

Case 15. Lapeyronie, Spring's paper, Obs. 51.-In this case a fungus followed the operation of trephining for injury. The dura mater had been wounded. Small portions of brain (nut) came away at each dressing for ten days. A cure of the hernia resulted. No treatment mentioned.

Case 16. G. B. Mallet, 'Trans. Prov. Med. and Surg. Assoc.,' vol. vii, p. 343.-J. B-, aged 18. Compound depressed fracture of vertex. Bone driven into brain removed. In eight days a growth from the brain appeared, persisted a week, discharged a piece of coal as large as a pea, and then gradually disappeared. No ill effects left.

Case 17. W. J. Goodeve, 'Lond. Med. and Phys. Journ.,' 1823, vol. 50, p. 191.-1st day.-Man aged 30. Scalp wound caused by falling stone, followed by symptoms.

6th.-Trephined; dura mater found puffed up ; opened. A quantity of serum seen collected under arachnoid.

8th.-Rigors; right hemiplegia becoming almost complete.

12th.-Hernia cerebri.

35th.-Hernia 2 inches in diameter and 2 inches in height.

46th.--Smaller from sloughing of its surface.

48th.-Sloughing continues. 
50th.-Bloody serous discharge.

60th.-Sloughing and bloody serous discharge continue.

69th.-A quantity of brain-like substance has found its way through a hole in the centre of the tumour. A probe passes into what was apparently an abscess cavity.

73rd.-Suppuration free; tumour lessening.

96th.-Continued shrinking; hardly any suppuration.

117th.-No vestige of tumour; wound healed.

After-result.-Epileptic fits at first, but the tendency diminished. When reported he had had none for twelve months, and was doing his work as a farm labourer. Paralysis evidently better.

CASE 18. Elcan, 'Amer. Journ. Med. Sci.,' April, 1880; Starr, 'Brain Surgery,' p. 183.-A boy suffered from a compound comminuted fracture of the left frontal bone, from which brain matter was expressed. In a few days hemiplegia and aphasia developed, and the boy became comatose.

Operation.-Bone elevated and portions removed. Hernia cerebri ensued; aphasia and hemiplegia remained, but consciousness was clear. Four days later the wound was again examined, and during its manipulation eight ounces of pus were suddenly evacuated from an abscess which unexpectedly broke. Subsequently the aphasia and paralysis subsided, the wound healed, and the boy recovered.

CASE 19. Ambroise Paré, Spring's paper, ' Mém. Acad. Royale de Méd. de Belge,' vol. iii, p. 70, 1854, Obs. 43. - A French seigneur, wounded at the siege of Metz in 1552, developed a fungus which came from the dura mater. It increased daily. The patient was perfectly cured.

\section{Cases left to Nature; Deaths.}

CASE 20. Marshall, 'Med. Times and Gazette,' 1875, vol. ii, p. 679. -February 23rd.-Man aged 14. Depressed compound fracture of left parietal bone with loss of brain substance from falling on a spike; trephined.

25th.-Temp. $103^{\circ}$; hernia cerebri formed; increased considerably.

26th.-Death.

Post-mortem.-Meningitis.

CASE 21. 'London Med. Gaz.,' 1829, vol. iv, p. 444.-A man aged 48 was operated on in the Glasgow Royal Infirmary for depressed 
compound fracture of the left parietal bone, and the dura was found wounded. He died on the sixth day of meningitis, just as a fungus was making its appearance. The wound was sloughy.

The fungus was the size of a pigeon's egg. It was of a dark brown colour, gradually turning to grey as it passed into the surrounding cerebral substance. Its central part was soft, and immediately around it the brain presented numerous bloody points; elsewhere the brain was firm.

Case 22. Abernethy, 'Surgical Observations,' p. 51.-Man aged 40 received a depressed fracture of the parietal bone from a falling stone. Operation. Delirium, followed by increasing coma, ensued. On tenth day a hernia cerebri rose through an ulcerated opening in dura mater; increased to size of a hen's egg. Death on twelfth day.

Post-mortem.-The tumour was larger than before, and of a dark colour. Hæmorrhage had taken pluce from the hernia into the dressings to a considerable extent. The tumour appeared to consist of coagulated blood of a fibrous texture, and to have originated within the substance of the brain about an inch below the surface. The pia mater was inflamed.

CASE 23. Abernethy, 'Surgical Observations,' "Injuries of the Head," p. 54.-A carpenter, in addition to other injuries, received a depressed compound fracture of the right parietal bone. The bone was trephined and elevated. Twelve days after the accident a hernia cerebri appeared rising through an aperture in the dura. It increased rapidly, and two days later he died.

Post-mortem.-Meningitis. The hernia cerebri was formed of congealed blood deposited in the medullary part of the cerebrum, the containing cavity being an inch in diameter, and its parietes appearing to be the substance of the brain condensed by pressure. The ventricles were full of a serous fluid mixed with blood.

Case 24. Bouchacourt, 'Bulletins de la Soc. Anat. de Paris,' 1838. vol. xiii, p. 13.-Man aged 32 had a severe fracture of the anterior part of the skull with injury to brain. On the sixth day inflammatory symptoms came on, and a cerebral hernia which had formed became inflamed and gangrenous, and separated in portions. On the granulating surface which formed, a fistulous track opened and discharged limpid fluid in drops. He began to go wrong on the twenty-fifth day, and died on the thirty-second of meningitis.

Post-mortem.-A short fistulous track traversed soft diffluent brain, which intervened between the surface of the wound, largely cicatrised, and the lateral ventricle. 
Case 25. G. W. Callender, 'Med.-Chir. Trans.'’ vol. liv, 1871, p. 132.-December, 1863.-Sailor aged 27. Fracture of skull. A month later trephined and pus liberated. Insensibility two months; loss of sight, followed by convulsive seizures and paresis of left limbs.

1864.--Removal of necrosed right parietal bone.

1866.-After an injury, complete paralysis of left side. Fits ceased.

1870.-Fell on his head when drunk. Next morning found a swelling on right side of skull, which steadily increased. Admitted into St. Bartholomew's a week later with hernia cerebri as large as a small orange. Had rigors; became noisy, then insensible, and died nine days after admission. Left-sided paralysis had persisted. Left eye blind. Right eye slight vision.

Post-mortem.-Evidence of long past meningitis. Softening of considerable portion of right hemisphere from which hernia cerebri protruded. The softening in places amounted to fluidity of brain tissue. Recent meningitis.

Case 26. Norris, 'Amer. Journ. Med. Sci.,' 1838-9, vol. xxiii, p. 279.-July 13th.-Woman aged 37. Trephined for depressed com. pound fracture of right temporo-parietal area. Dura slightly wounded. Paralysis of left arm and then left leg developed with other head symptoms.

August 1st.-Hernia cerebri.

16th.-Hernia as large as an egg.

19th.-Sloughing commencing at its top.

21st.-Lingering death.

Post-mortem.-Tumour arose from cerebrum, which it resembled in consistence and appearance. A large deep abscess existed in the cerebrum at the side of the tumour, and nearly the whole of that side of the brain was disorganised.

Case 27. Norris, 'Amer. Journ. Med. Sci.,' vol. xxv, p. 269.On July lst a boy aged 16 received a compound depressed fracture of the left side of the frontal bone an inch above the orbital ridge, an iron bolt being fixed in it. On its removal, and also some loose portions of bone, a portion of lacerated brain as big as a walnut protruded. There was right arm paralysis. The protrusion sub. sided until there was only a slight rising above the surface of the bone, and on the 19th the paralysis was entirely gone. Cicatrisation went on slowly till August 18th, when untoward symptoms developed, and he died on August 30th.

Post-murtem. - A fiagment of in-driven bone was pressing on the 
brain. An abscess occupied the whole anterior lobe. It contained 5 or 6 ounces of pus. The walls were lined by a thick false membrane. The cerebral matter around it was of a light yellowish colour and softened. Beneath the opening in the skull the dura was adherent to the brain, and the abscess was immediately beneath it. Ventricles much distended with serum. Right hemisphere normal.

CASE 28. Ward, 'Lancet,' 1848, vol. i, p. 305.-1st day.-Boy aged 7. Quoit accident. Compound fracture of left side of frontal bone. Depressed fragments removed. Superficial laceration of dura.

9th day.-Hernia cerebri formed.

12th to 23rd.-Pyæmic symptoms. Death.

Post-mortem.-At the base of the protrusion ${ }^{1}$ was a small abscess. Several purulent deposits in the lung.

Case 29. James Syme, 'Edin. Med. Journ.,' 1833, vol. xxxix, p. 315.-Man aged 28 received a depressed compound fracture of the right parietal bone with loss of brain substance. The depressed bone was removed. Paralysis of left arm and leg was followed by coma and death on the fourth day.

Post-mortem.-A cerebral hernia as large as a walnut. The convolutions of the subjacent brain, expanded, softened, and injected with blood, could be distinctly traced into the tumour, the principal part of which was composed of coagulated blood. The cerebral substance in the immediate neighbourhood of the injury was reduced to a pulpy consistence and tinged of a blood-red colour. In other parts nothing remarkable.

Case 30. Carmichael, 'Dublin Med. Press,' 1841, vol. v, p. 179.A man with a compound depressed fracture of the skull was not operated on for a fortnight when symptoms had appeared. Loose portions of bone were removed. The same stupid, listless state continued, and a few days later a fungus began to protrude through the opening. This was left alone, and in eight or ten days it declined, and finally disappeared. Death five weeks after the injury.

Post-mortem.-Where the fungus had existed there was a large slough, and the neighbouring parts of the brain were in a softened state.

1 This was supposed to be connected only with dura mater, the protrusion not containing cerebral structure. 
Case 31. Thorndike, 'Boston Med. and Surg. Journ.,' 1877, p. 82. - Man aged 32. Extensive compound depressed fracture of right parietal region with laceration of brain and symptoms of compres. sion, the result of a fall. Loose bone removed, leaving opening 3 inches by $2 \frac{1}{2}$ inches. Improvement followed. In a week palsy of left hand. This had been predicted because temperature had been $102^{\circ}$ in the left axilla and $99.9^{\circ}$ in the right, and this fact had been noted in other cases of palsy following head injury. In three weeks hernia cerebri developed, and grew to 4 inches in diameter. Palsy affected all the left side. Death from exhaustion eighty days from the accident. He became unconscious before death. No autopsy.

Case 32. Abernethy, 'Surgical Observations,' p. 38.-Boy aged 14 was trephined for depressed fracture of the anterior inferior angle of parietal and part of frontal bones. Middle meningeal hæmorrhage. On removal of clot the depressed dura mater rose to its original level, and bleeding ceased. He recovered consciousness towards the close of the operation. After some symptoms on the fifteenth day he had rigors and pain in the head, and next day a hernia cerebri was found protruding through the dura. It increased to the size of an orange in twenty-four hours. Death next morning. No post-mortem.

Case 33. G. Lowe, 'Lancet,' 1850, vol. i, p. 759.-Man aged 19. Extensive compound depressed fracture of skull from falling brick. Brain lacerated, and some escaped. Operation.

On eighth day symptoms of inflammation of brain became threat. ening, and a fungous growth appeared. Calomel freely given; inflammation of brain subsided, fungus sloughed away, leaving healthy granulating surface. In fourth week headache and fever, and reappearance of hernia ; then coma and death a month fiom the accident.

Case 34. Cæsar Hawkins, ' Lond. Med. Gaz.,' 1832, vol. x, p. 251. -Boy aged 11. Accidental shot, injury of face below the right eye. The middle fossa injured, and brain protruded into the cavity made by the bullet. On the seventh day it had protruded from the face wound to the size of a walnut along a track four inches long. Death on the eighth day.

Post-mortem.-The protrusion was in the usual soft and pulpy state of fungus of the brain, and the cerebrum around the softened part was vascular and of the yellow colour generally found in such cases. 
Cases in which Compression was the chief Treatment; Recoveries.

CASE 35. Bryant, ' New England Med. and Surg. Journal,' 1813, vol. ii, p. 280.-Hernia cerebri formed on the fourth day after the operation of trephining for fractured skull. It increased to the height of an inch, suppurating freely. Being lessened to half its size by suppuration, pressure was applied, and in a few days reduced it wholly, and the boy soon recovered.

CASE 36. R. M. Craven, 'Brit. Med. Journ.’’ 1865, vol. ii, p. 522 (reported by T. M. Evans).-March 1st.-Boy aged 15 was operated upon for depressed compound fracture of left parietal bone close to median line, with escape of brain substance.

2nd.-Complete paralysis of right arm and leg without anæsthesia and facial paresis.

3rd.-Right facial paralysis.

5th.-Considerable hernia cerebri.

12th.-Size of half an orange.

21st.-Paralysis of face less.

28th.-Slight pressure applied.

April.-Diminution of hernia ; paralysis improved.

May 2nd.-Hernia greatly reduced.

10th.-None left.

July 4th.-Wound healed; able to use arm, and walk.

Case 37. G. B. Mallet, ' Trans. Provincial Med. and Surg. Assoc.,' vol. vii, p. 343.-J. I-, aged 36. Portions of bone and coal which had penetrated the brain were removed from a compound depressed fracture of the frontal bone. Hernia cerebri on the tenth day. It reached the size of a walnut, and remained stationary till small portions of the inner table came away; then, assisted by slight pressure, it gradually disappeared, and the man recovered. Death from apoplexy five or six years later.

CASE 38. J. W. Heustis, ‘ Amer. Journ. Med. Sci.,’ 1828 or 1829. -Girl aged 10. Fungus followed a severe compound fracture of the skull, with escape of brain matter. He confined it with a strip of adhesive plaster over the protrusion. In a few days it dis. appeared, and the child recovered. 
Case 39. Bedford Brown, 'Amer. Journ. Med. Sci.,' New Series, vol. xl, p. 399.-Boy aged 10 was operated upon for a kick on the right side of the frontal bone. A large portion of bone was removed, lacerated dura mater cut away, and the brain found lacerated, and portions separated. Inflammatory symptoms in thirty-six hours, subsided in three or four days. On the eighth day a large fungus cerebri opened up the suppurating wound and filled the opening ( 2 inches $\times 1 \frac{1}{2}$ inches), and rose 1 inch above the bone. Sponge pressure was used, and in a few days the hernia had subsided, and in three or four weeks the wound was healed. Eight months later the patient was in good health.

Case 40. C. K. Crawford, 'Edin. Med. and Surg. Journ.,' vol. xii, 1816.-June 25th, 1813.-Boy aged 2 to 3 years trephined for depressed fracture of left parietal bone with loss of brain substance. Hernia cerebri beginning on fourth or fifth day grew rapidly to size of pullet's egg, and was increasing daily. By carefully applied pressure the tumour was much diminished in a few days, and receded very fast, the granulating surface eventually skinning over.

November, 1813.-Seen, and quite well.

Case 41. Moyle, 'Lond. Med. Reposit.', vol. viii.-Boy aged 10. March 15th.-Simple comminuted depressed fracture of left parietal hone. Symptoms of compression. Operation. Membranes penetrated by portion of bone, and brain matter discharged for three or four days.

22nd.-Fungus tumour appeared through the wounded meninges, and increased in two days to size of pullet's egg. It could be replaced by finger pressure. It was treated successfully by com. pression, carried ont for several weeks.

July 21st.-Well.

For twenty-three days after the accident he was senseless, with general paralysis of the whole body. Then his senses returned, and paralysis gradually disappeared. No convulsions at any time, and twenty-nine years later he was alive, and suffering no inconvenience from the brain injury.

Cast 42. R. W. Crighton, 'Lancet,' 1850, vol. i, p. 405.-September 4th.-Man aged 30 received a severe compound fracture of the frontal bone, which was accompunied by slight protrusion of brain substance.

5th.-Considerable cerebral protrusion.

6th.-During the next fortnight repeated protrusion, followed by sloughing, occurred. Then gentle pressure by a broad piece of 
strapping applied, with gradually increasing tightness, and by the end of the month the hernia was replaced by healthy granulations.

October 15th.-Healing; no tendency to protrusion.

Patient recovered.

CASE 43. Meldon, 'Dubl. Journ. Med. Sci.,' 1872, vol. liii, p. 295. -Boy aged 7. Double depressed fracture of skull in parietal and occipital regions; dura injured in the parietal wound. Bone elevated, and fragments removed. Three days later rigors and pain. 12th day.-Hernia cerebri appeared, and grew to size of a pigeon's egg. Pressure by lint and tea lead was used. Too much pressure caused convulsive movements. In two or three weeks it had entirely disappeared, and the wound closed. Complete recovery.

CASE 44. Weir, 'N. York Journ. of Med.,' 3rd ser., vol. vii, p. 291 (Case 3 from ' $N$. York Hosp. Records').-September 12th.-Boy aged 15. Compound depressed fracture of left side of frontal bone. Trephined. Two tablespoonfuls of brain matter escaped.

20th.-Hernia cerebri. Pressure employed, causing no symptoms. 27th.-Tendency to protrude ceased about this date.

November 17th.-Wound healed. Discharged cured.

CASE 45. A. G. Creagh, 'Lancet,' Feb. 21st, 1891, vol. i, p. 423.June 20th.-Hottentot boy. Fragments of bone removed from a compound fracture of the left parietal bone. The dura was extensively injured, and cortical substance protruded.

24th.-Paralysis of right arm, hand, and leg. Brain injury was situated over the motor area. Patient dull, apathetic; difficulty in expressing his ideas.

26th.-Convulsion.

29th.- Some sloughy brain substance removed from wound.

July 1st.-Hernia cerebri (walnut). Bandage pressure.

3rd.-Tongue protruded to right side.

16th.-Hernia size of fowl's egg. Paralysis complete.

August 26th.- Under continuous pressure the tumour has become level with the scalp.

September 1st.-The wound is skinning over. Gain in power in arm and leg.

October 30th.-Can walk with a crutch, and arm considerably improved. 


\section{Cases treated by Compression; Deaths.}

Case 46. Weir, 'N. York Journ. of Med.,' 3rd ser., vol. vii, p. 291 (Case 4 from ' N. York Hosp. Records ').-May 29th.-Man aged 24 received a compound depressed fracture of right parietal bone.

June 1st.-Trephined. Dura mater found lacerated, and brain protruded.

8th.-Protuberance in wound.

12th.-Convulsions.

16th.-Hernia reappeared from bandages slipping off; reduced by fingers, some pus and softened brain escaping.

17th.-Coma.

18th.-Death.

Post-mortem.-Purulent material was found around the receded tumour, and beneath it an abscess capable of lodging the last phalanx of the thumb. The brain substance around was softened. Both ventricles moderately distended with fluid. In other parts the brain was normal.

Cass 47. Cabot, 'Boston Med. and Surg. Journ.,' vol. lv, 227, 1856.-May 9th.-Man aged 25. Injury over right parietal bone.

31st.-Left-sided paresis and head pain.

June 3rd.-Operation. Portion of inner table had been detached. Pus evacuated from between dura mater and bone. Serious head symptoms continued during June.

July 4th.-Offensive slough removed.

5th, 6th.-Hernia cerebri. Scalp yielding to let it pass through.

7th. - As large as a hen's egg. Gave feeling of tluctuation.

8th.-It came off spontaneously. An abscess containing an ounce or more of thick bloody pus was found in its interior. Hernia cerebri continued to form in spite of sponge pressure. Portions died and were cut away or separated.

25th.-Death.

Post-mortem.-A large abscess cavity (diameter $1 \frac{1}{2}$ to 2 inches) containing small quantity of pus was found beneath the hernia. Its walls were pretty firm. The greater portion of the remainder of the hemisphere was markedly softened. There were numerous hæmor. rhages. The right crus was softened and swollen. The left hemisphere was normal.

CASE 48. Harvey, ' Lancet, 1846, ii, p. 503.-June 30th.-Man aged 30 , kicked by a horse. Compound depressed fracture of anterior inferior angle of left parietal bone with escape of brain substance.

vOL. IXXX. 
July 5th.-Symptoms led to trephining.

6th-19th.-Hernia cerebri (chestnut). Stationary. Superficial sloughing.

20th.-Hernià considerably increased. Speech more defective.

Paresis of right arm and probably leg; pain

20th-23rd.-Hernia increasing. Convulsions.

23rd-27th.-Hernia stationary. Speech and paresis improving.

Separation of slough.

28th.-Pressure applied.

August 1st.-Hernia rather smaller, measures $2 \frac{1}{2}$ inches by $1 \frac{3}{4}$ inches by $\frac{1}{2}$ inch in height.

7th.-Nearly level with scalp.

11th-13th.-Swelling formed above zygoma; thought to be protrusion of brain under skin. Slight increase of paralysis. Exfoliation of portions of dead bone. Skinning of wound advancing.

17th.-Rigor, coma, dilated pupils.

18th.-Sensible. Hernia increased, also paralysis.

23rd.-Downstairs. Arm useless. Protrusion receded to level of scalp.

25th-30th.-Paralysis improving. Enlargement of temporal region diminished.

October 2nd.-Vomiting. Hernia protruding again considerably. Very tense. Pieces of loose bone removed.

8th. - Hernia shrunk to level of scalp, but condition not satisfactory.

9th. -Death.

Post-mortem.-Hernia had sunk below scalp level, and the temporal swelling was entirely gone. An abscess containing a small frag. ment of bone and 2 ounces of pus was found in the left middle lobe. The overlying brain substance corresponding to the seat of injury was much softer than that adjacent to it. The abscess was surrounded by a hardened area.

CASE 49. Moyle, 'Lond. Med. Report,' vol. viii.-A miner had a considerable portion of the left parietal bone driven into the brain. It was removed. Hernia cerebri of considerable size formed in a few days, and was treated by gentle pressure. A sloughing came on, and in six weeks the wound was completely healed. Soon after the right side became completely paralysed, and eight weeks later he was seized with a violent pain in the head, and died in a short time. No post-mortem. 


\section{Cases treated by Caustics; Recoveries.}

Case 50. J. K. Sampson, 'Med. Times and Gaz.' 1858, vol. ii, p. 571.-November 5th, 1857.-Boy aged 12 admitted with depressed compound fracture of left side of frontal bone with laceration of membranes and brain. Symptoms occurred in four days as granu. lation advanced and loose bones came away. Hernia cerebri pro. truded until it overlapped the entire wound. It was treated by repeated dustings of dried sulphate of zinc and moderate pressure, and once when the dressings were left off for three hours the pro. trusion nearly reached its original size.

April 6th, 1858.-Left the hospital well.

Case 51. Volcher Koyter, Spring's paper, Obs. 47.-An excrescence formed at the third month in a man whose frontal bone and brain had been injured. It was treated with caustic lotions and other applications, but grew steadily. Towards the end of the eleventh month it ceased to reproduce itself. Cure resulted at the end of thirteen months.

Case 52. Weir, 'New York Journ. of Med.,' 3rd ser., vol. vii, p. 291 (Case 45, 'Hospital Records').-December 5th.-Man aged 24. Compound depressed fracture of left fronto-parietal region.

December 12th.-Trephined for symptoms of irritation and com. pression.

14th.-Hernia cerebri.

26th.-Has enlarged a little. Treatment: nitrate of silver and moderate pressure.

January 1st-10th.-Hernia decreasing slowly.

March 7th.-Discharged cured.

Case 53. Weir, 'New York Journ. of Med.,' 3rd ser., vol. vii, p. 291 (Case 32 from ' New York Hospital Records').-October 26th. -Female aged 22. Compound fracture of left parietal produced by hatchet, with wound of dura mater and brain, and paralysis of right arm.

27th.-Operation.

November 6th-28th.-Protrusion about the size of a hickory nut.

Nitrate of silver daily applied.

December 9th.-Reduced to level of integument.

27th.-Discharged cured. No paralysis remaining. 
CAse 54. Armour, ' Glasgow Med. Journ.,' 1831, vol. iv, p. 341.A man after operations for extensive depressed fracture of the skull suffered from a cerebral hernia which was treated by pressure and burnt alum. Progress was bad, and at last the surgeon said he was to be left alone, as he was dying. He was then insensible. Next morning he was much better. Nature's hint was taken and only simple dressings applied, and he eventually left the hospital well, but with somewhat weakened mind.

\section{Cases treated by Caustics; Deaths.}

Case 55. Emmanuel Koenig de Bâle, Spring's paper, Obs. 48.-A woman aged 40 developed a tumour, thought to be brain substance, after operative procedures for disease over the left temple. This increased daily; then the patient became drowsy, and died. It is to be inferred from Spring's paper that caustics were empioyed here.

Death was due to meningitis.

CASE 56. Moyle, 'Lond. Med. Reposit.,' vol. viii.-March 23rd.Boy aged 11. Depressed fracture of right parietal bone. Elevation and removal of loose pieces; large aperture in membranes, and escape of brain.

A pril 2nd.-Left-sided convulsions. Fungous tumour appeared, and in a few days grew to a considerable size. Coma present sub. sequently. Caustics and pressure of no use. He lingered with frequent and violent convulsions.

28th.-He expired in a fit.

\section{Cases treated by Various Operative Procedures, not} Removal; Recoveries.

CASE 57. J. E. Adams, 'Lancet,' 1876, vol. ii, p. 679.-Jew girl aged 7. Three months after a compound comminuted fracture of right fronto-temporal region with escape of brain substance, had a granulating pulsating mass as big as half a hen's egg projecting above the level of the skin. Pressure only flattened it out. It was covered by transplanting a flap of scalp on to it.

When reported, the size of the protrusion had much diminished, and no pulsation could be felt through the skin. The injury had been received in the early part of the year. 
CAsE 58. Folet, ' Lancet,' 1890, vol. ii, p. 669, Sept. 27th (Lawson refers to a case under Folet).-Hernia cerebri came on very rapidly, and was punctured in several places with the thermu-cautery, but without improvement. "The protruding mass, which consisted of granulation tissue, only gradually subsided, and cicatrised at the end of five months."

Case 59. Spaulding, 'New England Journ. Med. and Surg.,' vol. ix, p. 19, 1820.-A young man was trephined for compound depressed fracture of the frontal bone with injury to the mem. branes. Inflammation supervened, and on the fifth day the integuments began to rise, and the brain burst out, with coincident improvement in the patient's symptoms. If a compressive bandage was drawn too tight it caused violent twitchings of the whole body. The surface of the part protruded was daily pared off, with the loss of about a tablespoonful of blood. The hernia gradually receded within the skull, leaving a depression behind.

Spaulding attributed the good result to local depletion, and did not favour excision.

\section{Cases treated by Various Operative Procedures, not Removal; Deaths.}

Case 60. Weir, 'New York Journ. of Med.,' 3rd ser., vol. vii, p. 291 (Case 2, 'Hosp. Records').-March 30th._Man aged 36. Compound depressed fracture of left parietal bone with laceration of dura mater and brain. Inability to speak ; conscious; trephined.

April 1st.-Comatose; hernia cerebri protruding in a softened state, and easily detached. Female catheter introduced nearly two inches into brain, almost without resistance. No pus reached.

2nd.-Death.

Post-mortem.-The substance of the left hemisphere was broken up to the depth of $1 \frac{1}{2}$ inches below the fracture. No pus was seen.

The injury had been caused by a blow from a blacksmith's hammer.

Case 61. T. G. Coombe, 'Lond. Med. and Phys. Journ.,' 1816, vol. xxxvi, p. 449.-Boy aged 15. Operation for compound depressed fracture of frontal and left parietal bones with laceration of dura mater, followed by relief of compression symptoms. On tenth day hernia cerebri covered by pia mater burst through the healing wound. Compression symptoms returned, and increased with the 
growth of the tumour. Its unhealthy top was removed by a spatula, and a thin bloody fluid discharged for twenty-four hours to some ounces, and relieved the symptoms, sensibility returning. He had no return of these symptoms, but sank very fast, and died on thirtieth day.

Post-mortem.-A third of the left hemisphere at its anterior part was converted into a thick dark-coloured fluid, which appeared to consist of blood with brain in a state of suppuration.

Case 62. Detmold, ' Amer. Journ.,' 1830, Spring's paper, Obs. 56. -Three ounces of pus were let out from an abscess in the left anterior lobe of the brain. Hernia cerebri ten days later. Com. pression seemed satisfactory at first. Three weeks after operation loss of memory, aphasia, and other symptoms appeared, and hernia tended to return. Another incision failed to find pus, but symptoms were aneliorated, and the hernia subsided. Five days later it reappeared with shivering and coma. A fresh incision in the neighbourhood of the lateral ventricle let out three ounces of pus. Death in two hours.

Post-mortem.-Brain shrunk, normal aspect, and without alteration in its consistency. Both ventricles vere full of very liquid pus. Purulent lymph covered the choroid plexuses.

Case 63. Baudin, 'Gaz. Méd. de Paris,' 1840, p. 271.-A child aged 6 was run over and trodden on, receiving a compound fracture of the right temporal and parietal bone with loss of brain substance, on August 22nd. An abscess containing pus and shreds of brain matter opened on September 1st. Erysipelas followed, and the child died on September 11th.

Post-mortem.-A hernia cerebri was found to have passed through a gap in the centre of the depressed fracture. Meningitis.

Case 64. Cabot, ' Boston Med. and Surg. Journ.,' lxi, p. 181.Child aged $3 \frac{1}{2}$ years. Cerebral hernia occurred seven days after removal of bone from right frontal region for severe compound fracture with injury to brain. It increased in spite of sponge pressure. On twentieth day, fluctuation being present, an opening was made, and half an ounce of thin watery pus escaped. A fluid discharged constantly from the opening in the hernia, and on analysis was found indistinguishable from other serous fluids. Death on twenty. eighth day.

Post-mortem.-Meningitis. Nearly the whole of the anterior half of the right hemisphere, with the exception of the corpus striatum, was much softened. 
Case 65. Beevor and Horsley, 'Ophthal. Soc. Trans.,' vol. xii (1892), p. 204.-Christmas, 1890.-T. G. L-, aged 13, was trodden on the left side of his head by a horse. Symptoms pointing to intracranial mischief gradually came on and increased.

March 9th, 1891.-Admitted. Double optic neuritis; right hemianopia; drowsy and stupid. Adherent scar above external auditory meatus. Temperature subnormal. Pain.

13th.-Operation.-Fracture and portion of necrosed bone found. Considerable area of bone removed. Dura opened, pus found. Softened brain protruded (angular gyrus). Drainage-tube. Flap replaced.

24th.-Marked hernia cerebri. Wounds draining well.

April 22nd.-Mental condition improving.

May 12th.-Optic neuritis subsiding.

19th.-Evening temperature $103^{\circ}$. Wound tense; drowsy last three or four days. Explored; no definite collection of pus found. Wound freely opened. Extra drainage-tube inserted.

22nd.-Unconscious. Cheyne-Stokes respiration. Death in five hours.

Post-mortem. - Hernia involved parts of supra-marginal and angular gyri, \&c. Abscess cavity obliterated. Membrane adherent to surface of brain. Softening extended some distance into the brain adjacent to the protrusion. Basal suppurative meningitis.

Case 66. W. B. Husband, 'Assoc. Med. Journ.,' 1856, p. 355.February 29th.-Man aged 25 received a compound fracture of anterior superior angle of left parietal bone, with injury to brain, from a horse kick.

March 9th.-Fœtor of discharge.

11th.-Drowsiness. Right hemiplegia. Portions of loose bone removed by operation.

12th.-Aphasic symptoms. Hernia cerebri commencing.

13th-14th.-Increasing.

15th.-Looks sloughy.

16th.-Removed by patient's fingers.

27th.-Hernia cerebri size of pullet's egg; has sloughed ; ready to be detached; removed by forceps.

April 5th.-Gradually got weaker without much alteration in his mental condition (aphasia, paralysis). Death somewhat suddenly.

Post-mortem.-Meningitis. Brain corresponding to aperture in bone dark coloured and sloughy, but only superficially. Right hemisphere healthy. No mark of abscess in cerebral substance other than in immediate contiguity to the injured part. 
CAsE 67. Stanley, 'Lond. Med. Gaz.,' 1846, vol. ii, p. 1098.1st day.- Youth aged 17. Fall against a cart-axle produced an extensive depressed compound fracture of frontal and parietal bones on left side. Brain substance protruded. Other injury to bone from a horse kick. Depressed bone raised, and parts removed.

6th.-Recovery of consciousness. Continued to do well. A hernia cerebri formed and granulated, forming part of the surface of the wound.

19th.-Symptoms of inflammation of membranes; marked left facial paralysis.

25th.-Patient tore dressing off, and lacerated protruded brain with his fingers. Pulse became slow. Coma set in. Convulsions of right side of face.

33rd.-Death.

Post-mortem. - The left cerebral hemisphere was extensively dis. organised opposite the external wound, the disorganisation penetrating nearly to the lateral ventricle. The protruded brain was black and sloughy. Meningitis especially on left side and at the base. Fracture of the petrous bone might have caused facial paralysis. Abscesses in lungs.

CaSE 68. Ward, Lancet,' 1848, vol. i, p. 306.-Boy aged 13. 1st day.-Depressed compound fracture on right side of vault, with escape of cerebral substance. Operation.

11th.-Convulsions and paresis of left side appeared, and to.day hernia cerebri is forming.

15th.-Hernia size of large orange. "The protrusion was cut through the centre, and the knife passed an inch down into the substance of the brain." No matter escaped.

16th.-Death.

Post-mortem.-Hernia composed of brain softened and contused, mixed with irregular coagula of blood. Beneath, brain was soft and pulpy and tinged with blood to the extent of $1 \frac{1}{2}$ inches down and backwards from the surface. Meningitis. Secondary purulent deposits in lung.

Cases in which the Hernia was Removed; Recoveries.

Case 69. J. G. de Merveilleux, jun., 'Lond. Med. Reposit.,’ 1818, vol. ix, p. 283.-Boy aged 10 was wounded by a fork above the left frontal sinus. Two days later the wound was suppurating, and a probe passed four inches through the opening into the brain. 
Phrenitis supervened at the end of a month, and three weeks later hernia cerebri formed and increased to the size of a pigeon's egg in spite of frequent applications of lunar caustic and other escharotics. Then it was ligatured, and in a fortnight sloughed off. Dry lint dressing. The wound was well in ten days, and remained so.

CaSE 70. Webster, ' Lancet,' 1850, vol. i, p. 760.-A boy had to be trephined for a depressed fracture of the skull with laceration of dura mater and brain. Some protruded brain was removed. Hernia cerebri soon supervened, and required excision. The case ultimately recovered, and was seen by Webster thirty years later. The patient had had good health since the accident.

Case 71. Pring, 'Edin. Journ.;' Stanley, 'Med.-Chir. Trans.,' vol. viii.-Case in which a protruded mass (regarded as real hernia cerebri) was removed, and pressure employed. Cure effected.

Case 72. Stanley, 'Med.-Chir. Trans.,' vol. viii (1817).-Boy aged 11. 1st day.-Trephined for depressed fracture of frontal bone. Dura mater uninjured.

7th.-Cerebral hernia; pressure flattened it out.

8th or 9th.-Superficial portion-cortex and medulla-removed. Pressure applied.

10th or 11th.-Protrusion increasing. Whole mass now pared off at level of skull (medullary substance). Pressure continued, but still there was a tendency to increase, which ceased in about four days. The putrid surface now sloughed, and granulation and healing took place in a short tine.

Case 73. Spring's paper, Obs. 55. - A child came under M. Ficker's observation with a cerebral hernia (size of a goose's egg) on the left parietal bone fourteen weeks after the accident that led to it. There was complete right-sided paralysis. First local applications were tried. On the second day after removal of the destroyed part pressure by strapping applied. On the ninth day it was diminished one third. Ligature was now attempted, but as it produced convulsive movements and other symptoms, it was taken off. On the fifteenth day a fresh ligature was applied, and gradually tightened, and on the thirty-first the tumour came away. There was some necrosis of the edges of the opening, but this was no obstacle to cicatrisation, and healing was complete at the end of four months.

CAse 74. G. B. Mallet, 'Trans. Prov. Med. and Surg. Assoc.,' vol. vii, p. 343.-J. D-, aged 4. Compound depressed fracture of 
upper and central part of the frontal bone, with injury to brain. Paralysis of left side. Broken and loose portions of bone removed. In a week hernia cerebri, which increased to size of a duck's egg in spite of pressure and local applications. Remuined stationary for a fortnight, and was then removed by the knife. A spicule of bone was found projecting from the inner table, and was removed. After the operation there was a slight inclination to rise up, but it soon subsided, and the wound healed. The paralysis gradually disappeared. The tumour removed was evidently brain substance.

Case 75. Longmore, 'Brit. Med. Journ.,' 1882, vol. ii, p. 928.September 10th, 1879.-Male aged 39. Gunshot wound of right temporal region.

28th.--Supervention of left hemiplegia. No loss of sensation.

October 7th.-Paralysis had disappeared.

February 11th, 1880.-Invalided home. Wound discharging slightly.

April 8th.-Bullet and loose bone, \&c., removed.

July.-Small bernia cerebri with slender pedicle.

7th.-On probing by the side of the pedicle for loose bone " the tumour became quickly puffed up to the size of a marble, and giddiness, nausea, and headache were produced." These symptoms subsided on the following day, and the tumour returned to its previous size. Pressure could not be continued as it caused headache.

December.-Alarming cerebral symptoms. Status epilepticus. Operation. Ring of dura mater embracing pedicle was divided, and a piece of bone found firmly wedged between them. Brain explored for pus, none found. Hernia cerebri cut off. Incision in dura mater united. Rapid recovery.

January 2nd, 1881.-Wound healed.

Case 76. G. B. Mallet, 'Trans. Prov. Med. and Surg. Assoc.,' vol. vii, p. 343.-William H-, aged 12. Compound depressed fracture about the coronal suture (centre). Brain injured to depth of three-quarters of an inch. Paralysis of right side. Sight of right eye nearly gone. Loose portions of bone removed. In a week hernia cerebri began to form, and resisted all treatment till it measured 6 inches $\times 3 \frac{1}{2}$ inches $\times 2 \frac{1}{2}$ inches in elevation. Then removed by the knife as the patient was evidently sinking from con. stitutional irritation. Halfway through the knife encountered a small portion of loose bone. A few days later a disposition to protrude was controlled by pressure. The paralysis of leg began to 
mend. The wound was healed in eleven weeks from the accident. Slight la meness remained. The eye had perfect vision, but the arm remained useless.

The tumour was composed of brain substance-not so firm. as ordinary brain,- and had a cavity in its centre containing about an ounce of limpid serum. It was stated to be lined by a transparent membrane.

Case 77. Allen, 'New England Journ. of Med. and Surg.,' 1819, vol. viii, p. 323.- Man aged 19. A gun wad entered the brain about the posterior inferior angle of left parietal bone. Foreign substances were carefully removed. Hernia cerebri formed, and on the tenth day it closed the aperture in the bone, and prevented escape of discharges, and so led to pain, delirium and convulsions. Excised with relief of symptoms. Fungus cerebri gave no trouble, though caustic and moderate pressure were employed. Some months after the wound was " almost entirely sound."

Case 78. Lawson, 'Lancet,' September 27th, 1890, vol. ii, p. 669.May 13th, 1889.-Evacuation of subdural abscess due to necrosed bone six weeks after wound of left fronto-parietal region.

18th.-Hernia cerebri following symptoms.

August 6th.-Circumference of hernia cerebri 5 inches.

September 10th.-Pus found on probing hernia. Incision. Sym. ptoms apparently improved.

October 11th.- Portion shaved off and pressure applied.

31st.-Hernia only slightly altered in shape.

Norember 3rd.-In consequence of further pressure symptoms, an intra-cerebral abscess seems to have been opened with a director, and hernia was burnt off on a level with the skull.

5th.-Hernia the size of a Tangerine.

December. -Caustics applied.

February 12th, 1890.-Sinus found to lead into abscess cavity $2 \frac{3}{4}$ inches from surface. Drained.

13th.-Brain symptoms.

15th.-Hernia rapidly increasing, but symptoms better.

21st.-Caustics as before. Hernia gradually decreased till it was quite flush with the skull.

May 9th.-Went out.

Three weeks later healed completely.

CAst 79. John Adams, 'Lond. Med. Gaz.' vol. xxxiv, p. 336.Reference to a case by $\mathrm{Mr}$. Hill in which to prevent a repetition of 
bad symptoms he was obliged to shave away the tumour, and to push a lancet into its root as often as stupor and other symptoms showed that matter was lodged there, by which the patient was uniformly relieved, and eventually recovered.

Case 80. Mason, 'Lancet,' 1890, vol. i, p. 801.-September 19th, 1889.-Boy aged 6. Compound comminuted fracture of right frontal eminence from a horse kick. Portions of bone removed.

28th.-Hernia cerebri forming.

30th.-Rapidly increasing.

October 9th.-Size of Tangerine.

10th.-Sliced off level with skull.

22nd.-Larger than ever. Sliced off.

28th.-Again increasing. Firm bandaging caused slight but gradual diminution in size.

November 12th.-Level with surrounding skin. Wound healing. January 20th, 1890. - Went out well.

CASE 81. Maclaren, 'Clin. Soc. Trans.', 1886.-Man aged 26. 3rd day.-Depressed fragment of left frontal bone raised.

9th.-Loose fragments of skull removed, and hernia cərebri first cut off.

14th.-Right hemiplegia had developed.

23rd.-Hernia cerebri again cut off. Silver plate slipped inside skull.

42nd.-Hernia cerebri removed for the third time, and plate firmly fixed.

104th.-Plate finally removed.

A year later the leg had recovered, but the arm did not. Speecb fairly good, but slightly affected.

Case 82. Spring's paper, Obs. 45.-A youth of 14 develop ed a fungus after trephining for injury. A ligature caused it to fall off, but it was reproduced and was again similarly destroyed. Several times this was repeated until a mass the size of a fist had been removed. The patient, however, recovered.-Fabrice de Hilden. ${ }^{1}$

Case 83. Quesnay, 'Mem. of the French Academy of Surgery,' tome ii ; Stanley, 'Med.-Chir. Trans.,' vol.viii. Young man. 1st day.-Fracture of right parietal bone and wound of brain.

2nd.-Convulsions. Paralysis of opposite side, fever, delirium ;

1 Fabrice de Hilden relates also several similar facts, of which several treated by caustics ended in death ('Observat. Chir.,' Centur iv, O bs. 3, p. 289). 
injured brain black, swollen, and softened; protruded. Some of the projecting brain daily removed.

18th.-Fall from bed. The protruded gangrenous brain was detached and found in dressings. More gangrenous substance p rotruded through opening and was daily cut off.

35th.-When drunk patient tore away the protruded brain. Almost all the sloughy part was taken away. Recovery now set in, the exposed surface becoming red instead of black. The paralysis remained and he was subject to epileptic motions. Intellect perfect.

Case 84. Van Swieten, 'Commentaria,' tome i, p. 440 ; Stanley, 'Med.-Chir. Trans.', vol. viii, p. 37. Boy aged 14. Pus liberated by perforating skull two months after an injury. Hernia cerebri formed and cut off at its base by a thread. It was quickly reproduced and similarly removed. This was repeated several times until the mass removed equalled the size of a large orange.

The protrusion now ceased and the boy recovered.

Case 85. J. W. Heustis, 'American Journ. Med. Sci.,' 1828 or 1829 (two papers). Negro aged 8. On 5th day after operation for fracture of left parietal bone in which splinters had entered the brain substance, showed tendency to develop a fungus. As soon as it protruded above the skin level it was shaved off, and this had to be repeated every two or three days. Then it was left alone for a short time, but rapid growth continued, and it was again sliced away and sponge pressure applied. It now ceased to grow, and soon gave place to a large excavation in the brain, which rapidly filled up, the patient recovering perfectly.

Case 86. Porter, 'Dublin Med. Press,' 1839, vol. i, p. 54. . Mr. Roney, in a case of hernia cerebri, day after day sliced off the fungus, which day after day was renewed. The man recovered, after losing more brain than his skull could at any time have contained.

Remarks by Mr. Purter at a society.

CASE 87. W. W. Stewart, 'Philadelphia Journ. of Med. and Phys. Sciences,' vol. xii, p. 205, 1826.-Boy aged 9. Trephined for extensive compound depressed fracture of left parietal bone with wound of brain, caused by a horse kick.

16th day.-Hernia cerebri began to form, coincident with a recurrence of paralysis in the opposite arm and leg, and an aphasic condition. The hernia reached the bulk of a middle-sized orange, and was practically left to nature. 
35th.-Excision decided on. Removal in portions on four successive days. Protrusion continued, and the shaving-off plan was carried out at intervals for twenty days, when it showed signs of abating. A copious discharge oozed from the surface, and did not cease for three or four weeks. In the twelfth week the wound was healed, and the paralysis completely recovered in some mon ths. Mental condition unimpaired.

The boy was well three years later.

\section{Cases in which the Hernia was Removed; Deaths.}

CASE 88. Moyle, 'London Med. Reposit.,' 1817, vol. viii, p. 390. -Man aged 20. 1st day.-Compound depressed fracture of right parietal bone. Dura mater punctured by depressed bone. Trephined, and bone elevated.

4th.-Hernia cerebri grew to size of pigeon's egg.

11th.-Ligatured.

13th.-Tumour came away. No further protrusion.

24th.-Rigors, spasms.

33rd.-Pus escaped from brain, and when spasms came on it started out from a little hole in the direction of the fracture towards the ear.

40th.-Death.

No post-mortem, but superficial examination revealed nothing particular, except the abscess in the brain.

CASE 89. Cæsar H. Hawkins, 'Med.-Chir. Trans.,' vol. xxxix, p. 289.-Man aged 36, who had suffered from syphilis. On February 2 nd, 1832, had a pulsating tumour 5 inches in diameter on the upper and posterior part of the right side of his head. From its centre a small fungus protruded (walnut) through an opening in the scalp. There were other depressions in the bone on the other side, through which brain pulsations could be felt. The disease had begun two and a half years before admission. A depression in the bone first formed, and subsequently the tumour took its place. Eighteen months before admission pulsation was first pointed out to the patient. After various punctures at different times the fungus protruded through one of them. The fungus was removed by ligature, and then the tumour was similarly dealt with. Serious symptoms supervened. He died on the forty-seventh day after admission, when the tumour was increasing.

Post-mortem.-There were large apertures in the posterior part of the skull, which was much thinned. The anterior part was thickened 
and ivory-like. An opening from the centre of the fungus led into a large abscess in the right hemisphere, which had discharged itself during life. The disease had evidently begun in the bone.

Case 90. Pear'son, recorded by Stanley, 'Med.-Chir. Trans.,' vol. viii, p. 45.-November 12th, 1812.-Man aged 20, in Lock Hospital for syphilitic caries of frontal bone.

May 4th-12th, 1813.-Alarming head symptoms, relieved by treatment.

July 15th.-Necrosed bone easily removed. Hernia cerebri developed. No benefit from moderate pressure. Portions rendered loose by accident were cut away. The tumour increasing its base was ligatured, and tightened daily without rery obvious effect.

October 25th.-A large portion in a corrupted state accidentally broken off,

27th.-Stupidity, insensibility ; death.

Dimensions of tumour before the ligature $5 \frac{1}{2} \times 6 \frac{1}{2}$ inches, and 2 inches high.

Post-mortem.-An abscess containing between 2 and 3 ounces of pus was found in the anterior lobe of right heınisphere. Lateral ventricles contained some ounces of bloody fluid. The circumference of the hernia was much firmer than its centre. Opening in the bone $3 \times 2 \frac{1}{2}$ inches.

CASE 91. John Duncan, 'Brain,' 1879-80, vol. ii, p. 413.March 22nd, 1872.-Head injury.

May 11th.-Admitted with hernia cerebri ( $3 \frac{1}{2} \times 2 \times 1 \frac{1}{2}$ inches) over left parietal bone. Aphasic ; right side paralysed.

29th.-Serious symptoms set in; pyrexia, headache.

June 3rd.-Protrusion sliced off, and abscess cavity size of walnut exposed.

6th.-Death.

Post-murtem.-An abscess cavity occupied the superior parietal lobe; it contained diffluent brain matter and pus. The margins of an aperture in the bone were considerably depressed.

Case 92. Adamson, 'Med. Press and Circ.,' 1874, December 30th, p. 565.-August 23rd.-Man aged 19. Compound fracture of left parietal bone with laceration of brain and membranes.

September 5th.-Semi-coma came on. Spicule of bone projecting into brain removed. Consciousness soon returned.

22nd.-Wound nearly closed, but seemed fuller.

26th.-Hernia formed. Right hemiplegia ; vomiting. 
28th.-Shaved off level with scalp.

October 8th.-Hernia entirely disappeared. Semi-coma. 11th.-Death.

Post-mortem.-Abscess in left anterior lobe which had almost destroyed the third convolution and injured others. Congestion on surface of right hemisphere.

CAsE 93. Spring's paper, Obs. 54.-After the operation of trephining, when the brain had been injured, a hernia cerebri occurred. It was removed by a cutting instrument and the ligature, but grew again larger, and necessitated fresh operations at short intervals. Five or six ounces of brain matter were thus removed without accident. The tendency to reproduction did not diminish, and it was necessary to ablate nearly every evening. One night the patient was taken with delirium, shivering and insensibility, and died.

Post-mortem.-A large abscess had formed in the substance of the middle lobe, and had communicated with the ventricles, which were full of pus.

Reproduced from Chassaignac, 'Lésions traumatiques du Crâne,' Paris, 1842.

CAse 94. John Adams, 'Lond. Med. Gaz.' vol. xxxiv, p. 337 ; Dr. Tuthill's case ('Lond. Med. and Surg. Journ.,' 1831).-Hernia cerebri followed trephining for compound depressed fracture of left parietal bone. Its appearance was preceded by a violent attack of inflammation. After excision by ligature it was reproduced. After a large quantity of cerebral substance had been lost, compression was employed, and immediately produced paralysis of the opposite side, which continued until pressure was remitted. Death three weeks after the convulsive attack.

Post-mortem.-Abscess of middle lobe communicating with the ventricle.

Case 95. Stanley, 'Med..Chir. Trans.,' vol. viii, 1817.-Boy aged 12. Trephined for depressed fracture of skull.

10th day.-Hernia cerebri protruded and grew to size of small orange in three days. Partial insensibility. It was sliced off, and death occurred in three days.

Post.mortem.-Brain soft and broken where cut off, the condition extending into its substance. There was slight protrusion through the opening. Lateral ventricles large, and filled with transparent fluid. Meningitis.

The tumour cut off contained cortex, medulla convolutions, sulci. 
Case 96. Stanley, 'Med.-Chir. Trans.,' vol. viii, 1817.-Boy aged 13. 1st day.-Depressed fracture of frontal bone from kick of a horse.

2nd.-Operation. Bone elevated, and $3 \times 2$ inches removed. Dura uninjured.

7th.-Bulging dura mater sloughed.

8th.-Hernia cerebri size of ben's egg.

9 th and 10th. - Hernia cerebri increasing rapidly in spite of slight pressure.

10th-16th.-Removed at level of skull; firm pressure. Part removed composed of cortex and medulla, healthy in appearance. Surface sloughed, suppurated and granulated.

17th.-Drowsiness. Relaxation of pressure resulting in protrusion. Then restlessness and paralysis of left arm gradually developed.

24th-27th.-Considerable quantity of serous fluid (cerebrospinal) constantly oozed from the centre of the protrusion, trickling down the cheek in a stream. Hernia cerebri exceeded a large hen's egg in size. Gradual decline, and death on twenty-seventh day.

Post-mortem. - Arachnitis. The brain substance between the hernia and the anterior cornu of the lateral ventricle was soft and pulpy, and conveyed the idea of rottenness. All around the protrusion the brain had separated from the dura for a considerable space, and the tumour itself was considerably lessened in all its dimensions.

CAse 97. Douglas, ‘ Brit. Med. Journ.,’ 1874, p. 646.-Boy aged 18. August 5th.-Compound depressed fracture in region of anterior fontanelle with symptoms of compression. Removal of depressed fragments. Injury of right hemisphere by an embedded fragment.

6th.--Recovery from compression.

12th,-Suppuration. Piece of sloughing brain separating. Unconscious.

16th.-Conscious. Facial convulsive movements.

20th.-Hernia cerebri.

23rd.-General state improving. Hernia increasing.

28th.-Hernia increased in spite of pressure. Dimensions $3 \frac{1}{2} \times 2 \frac{1}{2}$ inches, circumference $6 \frac{1}{2}$ inches. Catgut ligature applied.

September 3rd. - Weaker. Separation expedited by knife. Tumour composed of broken-down, sloughy material, pus and blood. 10th.-Much weaker. Hernia protruding, and again removed. No further protrusion. Patient gradually got worse.

27th.-Death.

vOL. LXXX. 
Post-mortem.-A conical cavity extended vertically into the right hemisphere. Meningitis. Offensive odour.

Case 98. Dr. J. Thomson, 'Cooper's Surgical Dict.,' 6th edit., p. 690.-A soldier (?). Wound of right frontal bone with spicules of bone driven in upon the brain. A large fungus protruded. In the progress of the case escharotics were applied, and portions torn off by the patient. The part exterior to the cranium was twice pared off by the knife.

Post-mortem.-The whole of the right hemisphere was found converted into a soft pulpy mass. The left hemisphere was normal.

Case 99. Davidson, 'Edin. Med. and Surg. Journ.,' 1838, vol. 49, p. 41. August 1st.-Man aged 26. Trephined for compound depressed fracture of right parietal bone. Dura mater not injured.

29th.- Fungus is growing from the dura mater. Increase of left arm and leg paralysis.

September 3rd.--Removed with a scalpel. Consists of cerebral matter.

15th.-The cerebral fungus, which had recurred, was again sliced off. Removal of portions of exfuliated bone.

19th.-Further increase of tumour. Death.

Post-mortem. - The brain was disorganised throughout the whole of the middle and greater part of the anterior and posterior lobes. Corpus callosum involved, and the parts in the floor of the right lateral ventricles were converted into the same pultaceous reddish substance as the rest of the hemisphere. Each lateral ventricle contained a quantity of limpid serous fluid. The immediate seat of the protrusion was of a greenish-purple hue.

CAse 100. Armour, ' Glasgow Med. Journ.,' 1831. vol. iv, p. 341.A boy aged 15, after operation for a depressed compound fracture of the right frontal bone with injury to the brain and its membranes, developed a hernia cerebri on the 3rd day. On the 4 th it was torn away level with the bone. On the 6 th, having recurred, it was dug out considerably lower than the level of the cranium. Again recurring, it was shaved off for several days. In despair pressure was employed, but was given up because it caused compression symptoms. Then caustics were used till the twenty-third day, when the patient became insensible, had convulsions, and died.

Post-mortem.-The hernia had receded and left a deep cavity. The greater part of the substance of the right hemisphere was gone, 
its remaining surface being in a putrid-looking state. The brain substance was soft and more pulpy than natural.

Case 101. Porter, 'Dublin Med. Press,' 1839, vol. i, p. 114Six days after the accident, a man was trephined for fracture of the temple, pieces of bone being impacted in the brain. Next day a fungus formed and was removed. Reproduced to size of an orange ; was accidentally detached. Five times the fungus reappeared, and was removed by the patient himself or came away in the dressings. Amount lost $=4 \mathrm{oz}$. His symptoms were-he appeared heary, restless, answered questions unwillingly, had a slow pulse. He developed paresis of the opposite arm. After death the fungus, which had been prominent, began to sink until a hole $2 \frac{1}{4}$ inches deep was left.

Post-mortem.-The loss of brain substance reached to the lateral ventricle. During life after removal of one fungus a deep hole was observed in the brain, from which a clear serous fluid escaped in large quantity over patient's neck and arm. A large portion of the anterior lobe was destroyed, and the substance of the brain all round was highly vascular, and so soft that it was easily broken down by a touch of the finger.

On the opposite hemisphere an abscess containing 1 ounce of pus existed between the dura mater and the brain.

CASE 102. Prescott G. Hewett, 'Lancet,' 1864, vol. i, p. 24l.Hernia cerebri developed after separation of a large sequestrum, due to syphilis, from the frontal bone. The dura mater gave way.

The protrusion covered the eye, and in three weeks reached as low as the angle of the mouth. It was cut away, and other portions of brain soon followed, and were similarly dealt with. So matters went on when paralysis of the right side made its appearance. The patient sank in about a week after this.

Another case died four days after removal of the temporal bone, which was followed by hernia cerebri.

CASE 103. Spring's paper, Obs. 46.-Bartholini in 1649 records the case of a child of 4 , in whom extirpation of a double fungus was followed in a few days by death.

Case 104. Gwynn, 'Dublin Med. Press,' 1841, vol. v, p. 181.July 18th, 1837. - Man aged 25. Trephined for depressed compound fracture of the parietal bone, through which brain matter had been 
forced, and which had produced paresis of the right leg and con. vulsions.

20th.-Hernia cerebri showed itself.

25th.-Compression symptoms with increase of hernia. Hæmorrhage took place from it, and to prevent death from bleeding it was cut off close to its overlapping base, and styptics applied on lint. The tumour quickly recurred, and evidently was septic: Slight recurrence of hæmorrhage.

28th.-Death.

The tumour cut off was the size of half an orange, and consisted chiefly of blood and brain, the latter external to the former, and seemed to form the parietes of a cyst into which blood had flowed and coagulated.

Post-mortem.-The parts of the brain in the vicinity of the fracture were soft, pulpy, and mixed with blood.

Case 105. Moyle, 'Lond. Med. Reposit.,' vol. viii.-Boy aged 8. 1st day.-Compound depressed fracture involving both parietals. Operation. Large wound of membranes found. Escape of brain substance

6th.-Hernia cerebri ; convulsions. Compression failed.

11th.-Tumour removed by the knife; the hæmorrhage nearly proved fatal.

13th. $\rightarrow$ Death.

Case 106. Grimston, 'Lond. Med. Journ.,' 1789, vol. x, p. 277. -October 13th, 1788. Boy aged 4 was trephined for compound depressed fracture of right parietal and frontal bones, when the meninges were found injured, and portions of brain protruded. A few days later a fungus appeared, and was gradually reduced by solution of blue vitriol and pressure. Progress was satisfactory till early part of December, when it reappeared, and grew rapidly in spite of caustics and pressure, and was finally removed by ligature.

February, 1789.-Left facial paresis always relieved when matter escaped from the opening in the bones.

23rd.-Vomiting. Convulsions involving left arm and face. The fungus, which had grown as large as before. was incised, and an ounce of pus let out, but his condition continued unsatisfactory, and on March 11th further interference evacuated a large quantity of colourless fluid with some relief.

March 12th - The prominence was removed, but no further fluid appeared. The tumour grew again rapidly, and would not bear pressure. Vomiting, spasmodic affections, especially a rigidity of 
the neck, now made their appearance. The tumour gradually diminished, and became flaccid; yet the symptoms reduced him quickly, and he died on March 31st.

Examination of brain.-The wounds of the dura mater remained open. "The tumour had its origin from that membrane, to which it inseparably adhered. An empty cavity large enough to contain seven or eight ounces of fluid had been formed by the pressure of the tumour."

Remarks. -There is probably no doubt that this was a true hernia cerebri. Indeed, it is stated that the tumour resembled at one time brain, at another cartilage or steatoma. Death was probably due to meningitis, to which the operative procedures possibly contributed.

CASE 107. Van Swieten, Spring's paper, Obs. 49.-A fungus appeared on the fifth day in a boy of 7 after a fracture of the right parietal. It was treated by exsiccant remedies, and persisted for three months. At the beginning of the fourth month there was a considerable increase. It was then destroyed by caustics. In twenty-four hours it recurred bigger than before, and there was a return of cerebral symptoms. Caustics proving useless, the tumour was got rid of by ligature. This was followed by serious cerebral symptoms, and by the growth of a third tumour as big as a nut. In twelve days this had subsided and left an excavation in the brain substance. Two days later this was filled by a fourth fungus, and in a few more there was opisthotonos and death.

Case 108. Stephen Smith, 'New York Journ. of Med.,' 1857, 3rd ser., vol. ii, p. 83.-Man aged 40. 1st day.-Trephined for compound depressed fracture of right parietal bone. Dura mater found injured, and brain substance escaped.

4th.-Paralysis of left arm. Convulsions on paralysed side.

5th.-Fungus cerebri.

10th.-Fungus large. Convulsions have been frequent.

14th.-Paralysis has disappeared.

15th.-Fungus removed. No brain substance found in it. Com. posed of fibrin and hæmatoidin.

19th.-Removed again.

21st.-Removed again (possibly after sloughing).

22nd.-Paralysis of left arm came on.

33rd.-Condition unfavorable. Fungus reappeared, and continued to grow.

35th.-Paralysis extended to whole of left side.

37th.-Death with all the symptoms of abscess of brain.

No autopsy. 
CaSe 109. Weir, 'New York Journ. of Med.,' 3rd ser., vol. vii, p. 291, Case $\check{J}$ (practice of Dr. Buck).-Girl aged $6 \frac{1}{2}$.

May 22nd.-Depressed fracture of the left side of the frontal bone. 26th.-Trephined.

June 8th.-Hernia cerebri appeared, forcing open wound and the dura giving way.

17th.-Size of a hen's egg. Excised by ligature and scissors. (Cerebral substance. Microscope : no nerve tissue found, but cells and granules in quantity.)

23rd.-A jet of clear fluid forced from opening in the centre of the exposed brain, during crying. This was repeated several times, and it was supposed to come from the lateral ventricle.

28th.-Death. No autopsy, but the brain receded, leaving a hollow that would receive an egg, and the lateral ventricle opened into its floor.

(For report of the discussion on this paper, see 'Proceedings of the Royal Medical and Chirurgical Society,' Third Series, vol. ix, p. 108.) 